\title{
ClearColi as a platform for untagged pneumococcal surface protein A production: cultivation strategy, bioreactor culture, and purification
}

\author{
Valdemir M. Cardoso ${ }^{1}$. Sheyla A. H. Paredes ${ }^{1}$. Gilson Campani ${ }^{1,2} \cdot$ Viviane M. Gonçalves $^{3} \cdot$ Teresa C. Zangirolami $^{1}$
}

Received: 2 September 2021 / Revised: 24 December 2021 / Accepted: 28 December 2021 / Published online: 13 January 2022

(c) The Author(s), under exclusive licence to Springer-Verlag GmbH Germany, part of Springer Nature 2022

\begin{abstract}
Several studies have searched for new antigens to produce pneumococcal vaccines that are more effective and could provide broader coverage, given the great number of serotypes causing pneumococcal diseases. One of the promising subunit vaccine candidates is untagged recombinant pneumococcal surface protein A (PspA4Pro), obtainable in high quantities using recombinant Escherichia coli as a microbial factory. However, lipopolysaccharides (LPS) present in E. coli cell extracts must be removed, in order to obtain the target protein at the required purity, which makes the downstream process more complex and expensive. Endotoxin-free E. coli strains, which synthesize a nontoxic mutant LPS, may offer a cost-effective alternative way to produce recombinant proteins for application as therapeutics. This paper presents an investigation of PspA4Pro production employing the endotoxin-free recombinant strain ClearColi ${ }^{\circledR}$ BL21(DE3) with different media (defined, autoinduction, and other complex media), temperatures $\left(27,32\right.$, and $\left.37{ }^{\circ} \mathrm{C}\right)$, and inducers. In comparison to conventional $E$. coli cells in a defined medium, ClearColi presented similar PspA4Pro yields, with lower productivities. Complex medium formulations supplemented with salts favored PspA4Pro yields, titers, and ClearColi growth rates. Induction with isopropyl$\beta$-D-thiogalactopyranoside $(0.5 \mathrm{mM})$ and lactose $(2.5 \mathrm{~g} / \mathrm{L})$ together in a defined medium at $32{ }^{\circ} \mathrm{C}$, which appeared to be a promising cultivation strategy, was reproduced in $5 \mathrm{~L}$ bioreactor culture, leading to a yield of $146.0 \mathrm{mg}$ PspA4Pro/g dry cell weight. After purification, the cell extract generated from ClearColi led to 98\% purity PspA4Pro, which maintained secondary structure and biological function. ClearColi is a potential host for industrial recombinant protein production.
\end{abstract}

\section{Key points}

- ClearColi can produce as much PspA4Pro as conventional E. coli BL21(DE3) cells.

- $10.5 \mathrm{~g}$ PspA4Pro produced in ClearColi bioreactor culture using a defined medium.

- Functional PspA4Pro (98\% of purity) was obtained in ClearColi bioreactor culture.

Keywords Bioprocess engineering $\cdot$ ClearColi $\cdot$ Endotoxin-free Escherichia coli $\cdot$ Process conditions $\cdot$ Upstream · Recombinant protein

Valdemir M. Cardoso and Sheyla A. H. Paredes contributed equally to this work.

Teresa C. Zangirolami

teresacz@ufscar.br

1 Graduate Program of Chemical Engineering (PPGEQ), Department of Chemical Engineering, Federal University of São Carlos (UFSCar), Rodovia Washington Luís, km 235, São Carlos, SP 13565-905, Brazil

2 Department of Engineering, Federal University of Lavras, Lavras, MG 37200-900, Brazil

3 Laboratory of Vaccine Development, Butantan Institute, Av. Vital Brasil 1500, São Paulo, SP 05503-900, Brazil

\section{Introduction}

In the last decades, several studies have focused on the development of new pneumococcal vaccines with broader serotype coverage (Lagousi et al. 2019). Among the main objectives in such research, three are usually mentioned: (1) addressing a wider range of pneumococcal serotypes; (2) guaranteeing the immunization of children younger than 2 years old and older people, worldwide; (3) reducing the costs of producing and providing pneumococcal vaccines. A number of studies have indicated that these three main objectives may be addressed using a purified recombinant pneumococcal surface protein A (PspA) produced 
in Escherichia coli BL21(DE3) cells (Briles et al. 2000; Jedrzejas et al. 2001; Haughney et al. 2013; Perciani et al. 2013; Piao et al. 2014). Although different adjustments in upstream and downstream processes have provided reliable PspA production (Carvalho et al. 2012; Campani et al. 2016; Figueiredo et al. 2017; Cardoso et al. 2020), the presence of lipopolysaccharides (LPS) in the outer membrane of $E$. coli cells commonly used as platforms for recombinant protein production remains an obstacle to obtaining therapeutics at an industrial scale. LPS may cause an endotoxin response in humans, even at extremely low concentrations (Taguchi et al. 2015). The LPS structure consists of three regions: a core polysaccharide, an external long-chain polysaccharide, and a nonpolar lipid (lipid A) that is the portion of the molecule responsible for toxicity (Schneier et al. 2020). Lipid A binds toll-like receptor 4 (TLR4), triggering the production of proinflammatory cytokines and activating the coagulation cascade, which can lead to septic shock and death (Ramachandran 2014). For this reason, there are strict regulations worldwide regarding the LPS content in biopharmaceutical products. There are several approaches to reduce LPS content during downstream processing, including ultrafiltration, extraction, membrane adsorption, and ion exchange and affinity chromatography (Schneier et al. 2020). However, LPS removal represents a unique challenge, as the lipopolysaccharides form stable interactions with themselves and (depending on the characteristics of the protein) with the target molecule, leading to lower recovery and productivity (Schneier et al. 2020). Hence, there is no general procedure for dealing with LPS impurities in cell extracts, with the method having to be defined on a case-by-case basis.

In 2013, an endotoxin-free Escherichia coli strain named ClearColi ${ }^{\circledR}$ BL21(DE3) (Lucigen 2016) was released onto the market. Due to several genetic deletions, ClearColi cells produce a modified LPS called lipid $\mathrm{IV}_{\mathrm{A}}$, which contains four acyl chains, instead of six, and the oligosaccharide chains are deleted. Lipid $\mathrm{IV}_{\mathrm{A}}$ does not cause an endotoxin response in humans (Watkins et al. 2017b) and may evidently allow simpler downstream processes, compared to the use of conventional $E$. coli cells, in the production of recombinant proteins (Mamat et al. 2015). However, ClearColi ${ }^{\circledR}$ BL21(DE3) cells have slower growth rates (Lucigen 2016), which may decrease upstream productivity in terms of both biomass and recombinant proteins (Ueda et al. 2016).

To date, most of the published studies with ClearColi ${ }^{\circledR}$ BL21(DE3) have been restricted to complex medium formulations and shake flask cultures to produce enzymes (Liang et al. 2015; An et al. 2019; Jobin et al. 2019; Song et al. 2019), antigenic proteins (Martínez-Donato et al. 2016; González-Miro et al. 2017; Viranaicken et al. 2017; Watkins et al. 2017b, 2017a; Abdellrazeq et al. 2019, 2020), and therapeutic products (Mamat et al. 2015; Planesse et al. 2015; Ueda et al. 2016; Pooe et al. 2017; Tomczak et al. 2017; Wang et al. 2017; Hunt et al. 2019;
Wilding et al. 2019a, 2019b; López et al. 2021; Nguyen et al. 2021). ClearColi® BL21(DE3) has also been used to produce diagnostic biomolecules (Masarapu et al. 2017; Yoo et al. 2017; Park et al. 2021) and in specific functional studies (Moon et al. 2018; Bong et al. 2019; Hayashi et al. 2019; Kobayashi et al. 2019; Qiao et al. 2019; Carratalá et al. 2021; Hsu et al. 2021; Segovia-Trinidad et al. 2021), among other uses (Ran et al. 2019; Sankaran et al. 2019; Sankaran and del Campo 2019; Gnopo et al. 2020). On the other hand, studies have demonstrated that the production of recombinant proteins in conventional E. coli cells is affected by several process factors (Kaur et al. 2018) that may impact yields and titers, as well as lead to the formation of inclusion bodies and poor protein quality (Rosano and Ceccarelli 2014). Therefore, a survey of the performance of ClearColi ${ }^{\circledR}$ BL21(DE3) under different cultivation conditions is required, envisioning its potential as a platform for recombinant protein production. This paper presents the results of PspA4Pro production using ClearColi ${ }^{\circledR}$ BL21(DE3), considering the effects of relevant process conditions including cultivation temperature $\left(27,32\right.$, and $\left.37{ }^{\circ} \mathrm{C}\right)$, medium composition (defined and complex), inducers (lactose and isopropyl- $\beta$-Dthiogalactopyranoside (IPTG)), and scale (0.5-L shake flasks and 5-L stirred-tank reactor (STR)). In addition, the comparison was made of PspA4Pro production using conventional E. coli BL21(DE3) and ClearColi cells in a defined medium, with an assessment of the quality of the target protein obtained in the two systems.

\section{Materials and methods}

\section{Microorganisms}

Cultivations were performed with conventional $E$. coli BL21(DE3) (Invitrogen, Carlsbad, CA, USA) and ClearColi ${ }^{\circledR}$ BL21(DE3) (Lucigen, Tucson, AZ, USA) harboring the plasmid pET37b(+) (Novagen), carrying the $\mathrm{N}$-terminal domain plus the first proline block of PspA4Pro gene (GenBank EF649969.1), an untagged fragment of the PspA gene from family 2 , clade 4 , designated as PspA4Pro (Moreno et al. 2010). The recombinant plasmid pET37b(+)pspA4Pro was extracted from conventional E. coli BL21(DE3) cells and transformed by electroporation into ClearColi ${ }^{\circledR}$ BL21(DE3) cells, according to the manufacturer's instructions (Lucigen 2016). The promoters LacUV5 and T7lac controlled the production of the recombinant protein, which was accumulated intracellularly after the addition of the inducer (IPTG or lactose) (Campani et al. 2017; Figueiredo et al. 2017). The conventional recombinant E. coli strain was kindly provided by Dr. Eliane Miyaji from the Laboratory of Molecular Biology, Butantan Institute (São Paulo, Brazil). 


\section{Experimental strategy}

Firstly, shake flask experiments were carried out with a defined medium, in order to assess the effects of the inducers and temperature on ClearColi culture, as well as its performance in comparison to conventional E. coli BL21(DE3) cells, in terms of PspA4Pro production. Figure 1 presents a flow diagram representing the experimental strategy adopted in this work. A 2-level full factorial experimental design (Rodrigues and Iemma 2014; Montgomery 2013) having cultivation temperature and induction strategy (type of inducer, lactose or IPTG, combined with its concentration) as factors was set up to study PspA4Pro production in a defined medium. Runs according to each of the five selected conditions described in the experimental design matrix (step I, Fig. 1) were carried out for each host platform (ClearColi or conventional E. coli BL21(DE3) cells). The most promising production condition using ClearColi cells was then scaled up and evaluated in a bioreactor culture (step II, Fig. 1). The PspA4Pro obtained from this bioreactor cultivation was purified and characterized in terms of its secondary structure and biological activity. Additional shake flask experiments were also carried out to evaluate the influence of medium enrichment on PspA4Pro production and biomass formation in ClearColi cultures (step III, Fig. 1). Usual complex media including LB-Miller (LB), autoinduction ZYM-5052 (Studier 2005), and other medium formulations based on them (Table 1) were investigated. Nitrogen sources such as yeast extract and peptone present in complex formulations may influence biomass growth and product formation, due to the presence of amino acids and peptides in their compositions. Since peptones may have different peptides and carbohydrates in their formulations, the investigation was made of the replacement of tryptone by soy-based peptone in modified LB (LBM) and ZYM-5052 media. The experiments with different complex media were carried out at $32{ }^{\circ} \mathrm{C}$, which was selected in step I. Moderate temperatures have been demonstrated to improve PspA4Pro production in conventional E. coli BL21(DE3) cultures, increasing cost-effectiveness (Campani et al. 2017; Cardoso et al. 2020). The compositions of all the media studied are shown in Table 1. In general, for the defined and complex media, induction was performed using a pulse of $1.0 \mathrm{mM}$ IPTG or $5.0 \mathrm{~g} / \mathrm{L}$ lactose. Alternative induction protocols in cultures carried out with complex (pulse of $0.5 \mathrm{mM}$ IPTG or $2.5 \mathrm{~g} / \mathrm{L}$ lactose) and defined (pulse of $0.5 \mathrm{mM}$ IPTG plus $2.5 \mathrm{~g} / \mathrm{L}$ lactose) media were also evaluated at $32{ }^{\circ} \mathrm{C}$. Control experiments were carried out without induction.

\section{Shaker cultivations}

All shaker cultivations were carried out using solely either complex (for ClearColi cells) or defined (for ClearColi and conventional BL21 DE3 E. coli cells) media in all steps. Colonies were incubated in plates containing agar and LB or defined medium, plus kanamycin. Afterwards, to start the inoculum preparation, a single colony was transferred to a sterile $0.5-\mathrm{L}$ Erlenmeyer flask containing $30 \mathrm{~mL}$ of $\mathrm{LB}$ or defined medium, plus antibiotic, and incubated overnight at $37{ }^{\circ} \mathrm{C}$ and 250 revolutions per minute (rpm), up to optical density $600 \mathrm{~nm}$ (OD) of approximately 2.0. A defined volume of the inoculum was then transferred to start the cultivation with the desired medium at an OD of 0.1 (Table 1). The experiments were performed in sterile $0.5-\mathrm{L}$ Erlenmeyer flasks containing 50 and $70 \mathrm{~mL}$ of complex and defined media, respectively, at initial $\mathrm{pH}$ of 6.3 . The flasks were incubated at the established temperatures $(27,32$, and $37{ }^{\circ} \mathrm{C}$ ), with agitation at $350 \mathrm{rpm}$. When the OD reached approximately 2.0 , synthesis of the recombinant protein was induced by a pulse of inducer (lactose or IPTG) or after the depletion of glucose during auto-induction cultivations in ZYM-5052 medium containing $5.0 \mathrm{~g} / \mathrm{L}$ of lactose (Table 1).

\section{Bioreactor cultivation}

The bioreactor cultivation using ClearColi ${ }^{\circledR}$ BL21(DE3) followed procedures similar to those described previously by Cardoso et al. (2020) for conventional E. coli BL21(DE3) cultures. A single bacterial colony was transferred from an agar plate containing defined medium and kanamycin to a 0.5 -L Erlenmeyer flask containing $30 \mathrm{~mL}$ of the defined medium, with incubation overnight (pre-inoculum) at $37^{\circ} \mathrm{C}$ and $250 \mathrm{rpm}$. When an optical density (OD at $600 \mathrm{~nm}$ ) of 2.0 was reached, the required volume was transferred to start the inoculum culture at OD of 0.1, in three 0.5-L Erlenmeyer flasks, each containing $100 \mathrm{~mL}$ of defined medium. These flasks were incubated under agitation at $350 \mathrm{rpm}$, until reaching $\mathrm{OD}$ of 2.0 , before inoculating $3.5 \mathrm{~L}$ of the defined medium into the bioreactor, in order to start the cultivation with an initial OD of 0.05. A 5-L stirred-tank reactor (STR) controlled and monitored by SuperSys_HCDC software (Horta et al. 2014) was used. The temperature was set at $32{ }^{\circ} \mathrm{C}$, monitored with a thermocouple, and controlled using water from a thermostatic bath passed through the bioreactor jacket. The $\mathrm{pH}$ was automatically controlled at 6.3, using solutions of $\mathrm{NH}_{4} \mathrm{OH}(15 \% \mathrm{v} / \mathrm{v})$ and $\mathrm{HCl}(9 \% \mathrm{v} / \mathrm{v})$. Dissolved oxygen was measured with an amperometric probe (Model InPro 6830, Mettler Toledo) and maintained at 30\% of saturation by adjusting the stirrer speed and the air and oxygen flow rates (Cardoso et al. 2020).

When the OD reached approximately 20 , the induction was performed by the addition of $0.5 \mathrm{mM}$ IPTG plus $10 \mathrm{~g} / \mathrm{L}$ lactose. To avoid hampering protein synthesis due to carbon source depletion, a pulse of $300 \mathrm{~mL}$ of defined medium with $500 \mathrm{~g} / \mathrm{L}$ glycerol was added after $3 \mathrm{~h}$ of induction. 
I) Screening induction conditions using defined medium (shake-flasks)

2-level factorial design (CC and CV, in duplicate) at $32^{\circ} \mathrm{C}$

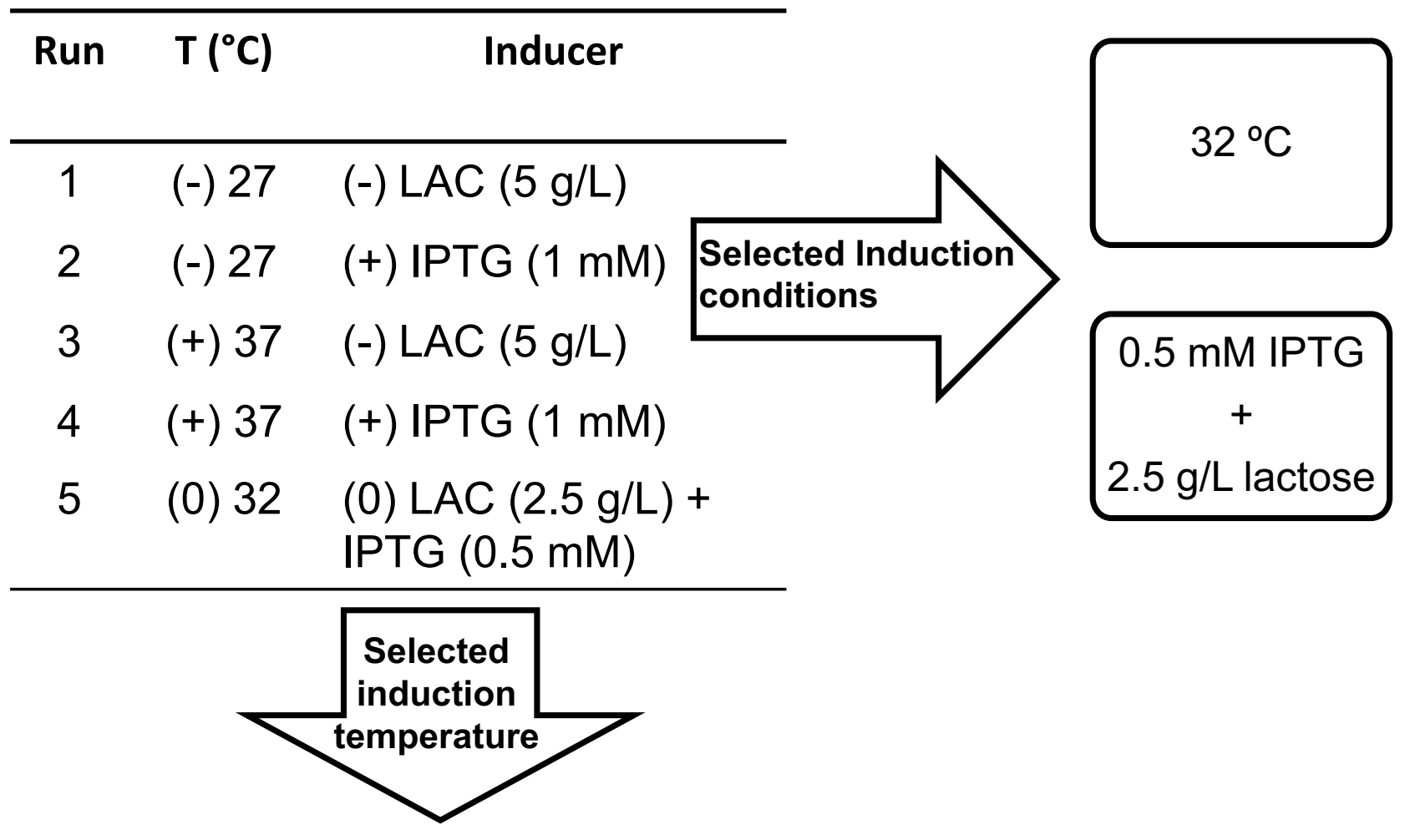

II) CC bioreactor culture + purification

\section{III) ClearColi performance in complex media}

Survey of complex media

(1 mM IPTG, $32^{\circ} \mathrm{C}$, duplicate)

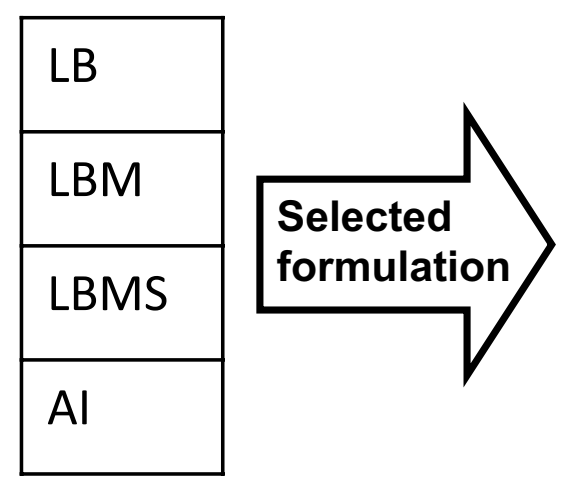

Induction strategy with lactose: pulse and Al (LBMS, $5 \mathrm{~g} / \mathrm{L}, 32^{\circ} \mathrm{C}$, duplicate)

\begin{tabular}{|l|l|l|}
\hline $\begin{array}{l}\text { Alternative } \\
\text { induction } \\
\text { strategies }\left(\mathbf{3 2}{ }^{\circ} \mathrm{C},\right. \\
\text { pulse, duplicate): }\end{array}$ & Medium & Strategy \\
\cline { 2 - 3 } & LBM & $0.5 \mathrm{mM}$ IPTG \\
\cline { 2 - 3 } & LBMS & $0.5 \mathrm{mM}$ IPTG \\
\cline { 2 - 3 } & LBMS & $2.5 \mathrm{~g} / \mathrm{L}$ lactose \\
\hline
\end{tabular}

Temperature influence: - $1 \mathrm{mM}$ IPTG (LBMS, pulse, $27 \& 37^{\circ} \mathrm{C}$ ) - $5 \mathrm{~g} / \mathrm{L}$ lactose 
४Fig. 1 Overview of experimental strategy in three steps: (I) Screening upstream conditions for ClearColi BL21(DE3) - CC - and conventional $E$. coli BL21(DE3) - CV-cells in shake flasks using defined medium; (II) scale-up for CC cultivation in 5-L stirred-tank bioreactor and PspA4Pro purification; (III) ClearColi performance in complex media in shake flasks using complex media. AI, auto-induction medium; IPTG, isopropyl- $\beta$-D-thiogalactopyranoside; $L A C$, lactose; LBM, modified LB medium, in which tryptone was replaced by soy peptone; LBMS, LBM supplemented with salts; T, cultivation temperature

\section{PspA4Pro purification and quality assessment}

For characterization of the quality of the PspA4Pro produced in the ClearColi culture, the cell pellet harvested at the end of the bioreactor culture was stored at $-80^{\circ} \mathrm{C}$. Subsequently, $100 \mathrm{~g}$ (wet basis) of frozen cell pellet was resuspended in $1 \mathrm{~L}$ of lysis buffer $(10 \mathrm{mM}$ sodium phosphate; $2.5 \mathrm{mM}$ ethylenediamine tetraacetic acid (EDTA); $0.1 \%(\mathrm{w} / \mathrm{v})$ Triton $\mathrm{X}-100 ; 1 \mathrm{mM}$ phenylmethylsulfonyl fluoride; $\mathrm{pH} 6.5$ ) and the resulting suspension was disrupted using a high-pressure homogenizer (Figueiredo et al. 2017). After clarification, PspA4Pro from the clarified extract was purified by anion exchange chromatography and cryoprecipitation (Figueiredo et al. 2017; Benedini et al. 2020). The PspA4Pro secondary structure was analyzed by circular dichroism (CD), according to the procedures described by Figueiredo et al. (2017). The biological activity was evaluated by lactoferrin binding assay, as described previously by Cardoso et al. (2020). The immunization and bleeding protocols to obtain rabbit antiPspA4Pro serum followed the rules issued by the National Council for Control of Animal Experimentation (CONCEA) and were approved by the Ethics Committee on Animal Use of the Butantan Institute (CEUAIB n ${ }^{\circ} 7,755,300,718$ ).

\section{Analytical methods}

The biomass concentration $\left(\mathrm{C}_{\mathrm{X}}\right)$ was monitored by optical density measurements at $600 \mathrm{~nm}$ and by the dry cell weight (DCW) method (Olsson and Nielsen 1997). A minimum amount of two samples were evaluated for each measurement.

Soluble and insoluble PspA4Pro production was followed throughout the experiments. After cell disruption by sonication and clarification (Campani et al. 2016), total protein in the supernatant was determined by the Bradford method (Bradford 1976), while the content of each protein was identified using $12 \%$ sodium dodecyl sulfate-polyacrylamide gel electrophoresis (SDS-PAGE) stained with Coomassie Blue R (Laemmli 1970), where PspA4Pro band appears at approximately $50 \mathrm{kDa}$ (Moreno et al. 2010; Figueiredo et al. 2017). The soluble PspA4Pro titer $(\mathrm{mg} / \mathrm{L})$ was estimated by the combination of stained gel band densitometry results (Abràmoff et al. 2004) and the total soluble protein concentration
(Campani et al. 2016). The product yield ( $\mathrm{Y}_{\mathrm{p} / \mathrm{x}} \mathrm{mg} / \mathrm{gDCW}$ ) and productivity $\left(\mathrm{P}_{\mathrm{P}}, \mathrm{mg} /(\mathrm{L} . \mathrm{h})\right)$ were obtained as the ratios between the PspA4Pro titer and the corresponding biomass concentration and cultivation time, respectively. In addition, the insoluble fraction obtained after sonication was resuspended in Tris- $\mathrm{NaCl}$ buffer $(20 \mathrm{mM}$ Tris; $250 \mathrm{mM} \mathrm{NaCl}$; $\mathrm{pH}$ 8.0) and the presence of insoluble PspA4Pro as inclusion bodies was analyzed using 12\% SDS-PAGE stained with Coomassie Brilliant Blue R, as described by Cardoso et al. (2020). A minimum amount of two samples were evaluated for each quantification of protein concentration.

The concentrations of glycerol, lactose, glucose, acetate, and lactate were determined using a high-performance liquid chromatography (HPLC) system equipped with an Aminex HPX-87H column (Bio-Rad), at $50{ }^{\circ} \mathrm{C}$. The mobile phase was $5 \mathrm{mM}$ sulfuric acid solution, at a flow rate of $0.6 \mathrm{~mL} /$ min. Glycerol and sugars were identified using a refractive index detector (model 410, Waters), while organic acids were monitored at $210 \mathrm{~nm}$ using an ultraviolet detector (model 486, Waters).

\section{Statistical analysis}

The experimental results were expressed as means and standard deviations. Shake flask experiments at $32{ }^{\circ} \mathrm{C}$ were carried out as genuine duplicates, from plates to submerged cultures. For all flask experiments, at least two samples were evaluated for each analysis of biomass formation and protein production. The standard deviation for experiments at 27 and $37^{\circ} \mathrm{C}$ was estimated by propagating the central point $\left(32^{\circ} \mathrm{C}\right.$ condition) deviation as a relative error. For the bioreactor culture, triplicate samples were used in all analyses. Statistical differences were evaluated using ANOVA followed by Tukey's test, with a significance level of $p<0.05$.

\section{Results}

\section{PspA4Pro production in a defined medium using ClearColi ${ }^{\circledR}$ BL21(DE3)}

The production of PspA4Pro in bioreactor cultures using conventional E. coli BL21(DE3) cells and defined medium has been extensively studied by our research group (Campani et al. 2016, 2017, 2019; Figueiredo et al. 2017; Benedini et al. 2020; Cardoso et al. 2020). However, no reports in the literature were found for the cultivation of ClearColi ${ }^{\circledR}$ BL21(DE3) using a chemically defined medium with glycerol as a carbon source. Therefore, the studies with ClearColi started with the characterization of its performance in a defined medium with glycerol, using shake flasks, with a screening of different cultivation temperatures and inducers 
Table 1 Initial compositions of the media

\begin{tabular}{|c|c|c|c|c|c|c|}
\hline Substance & Unit & Defined & Auto-induction & LBMS & LB & LBM \\
\hline Glycerol & $\mathrm{g} / \mathrm{L}$ & $20.0 / 60.0^{*}$ & 20.0 & 20.0 & - & - \\
\hline Glucose & $\mathrm{g} / \mathrm{L}$ & - & 0.5 & - & - & - \\
\hline Tryptone & $\mathrm{g} / \mathrm{L}$ & - & - & - & 10.0 & - \\
\hline Soy peptone & $\mathrm{g} / \mathrm{L}$ & - & 10.0 & 10.0 & - & 10.0 \\
\hline Yeast extract & $\mathrm{g} / \mathrm{L}$ & - & 5.0 & 5.0 & 5.0 & 5.0 \\
\hline $\mathrm{NaCl}$ & $g / L$ & - & - & - & 10.0 & 10.0 \\
\hline $\mathrm{MgSO}_{4}$ & $\mathrm{~g} / \mathrm{L}$ & 1.6 & 0.5 & 0.5 & - & - \\
\hline $\mathrm{KH}_{2} \mathrm{PO}_{4}$ & $\mathrm{~g} / \mathrm{L}$ & 17.7 & 3.4 & 3.4 & - & - \\
\hline $\mathrm{NH}_{4} \mathrm{Cl}$ & $\mathrm{g} / \mathrm{L}$ & - & 2.7 & 2.7 & - & - \\
\hline $\mathrm{Na}_{2} \mathrm{HPO}_{4} \cdot 12 \mathrm{H}_{2} \mathrm{O}$ & $\mathrm{g} / \mathrm{L}$ & - & 9.0 & 9.0 & - & - \\
\hline $\mathrm{Na}_{2} \mathrm{SO}_{4}$ & $\mathrm{~g} / \mathrm{L}$ & 17.7 & 0.7 & 0.7 & - & - \\
\hline$\left(\mathrm{NH}_{4}\right)_{2} \mathrm{HPO}_{4}$ & $\mathrm{~g} / \mathrm{L}$ & 5.3 & - & - & - & - \\
\hline Citric acid & $\mathrm{g} / \mathrm{L}$ & 2.3 & - & - & - & - \\
\hline $\mathrm{Fe}(\mathrm{III})$ citrate & $\mathrm{mg} / \mathrm{L}$ & 133.3 & 100.8 & 100.8 & - & - \\
\hline $\mathrm{CoCl}_{2} \cdot 6 \mathrm{H}_{2} \mathrm{O}$ & $\mathrm{mg} / \mathrm{L}$ & 3.3 & 2.5 & 2.5 & - & - \\
\hline $\mathrm{MnCl}_{2} \cdot 4 \mathrm{H}_{2} \mathrm{O}$ & $\mathrm{mg} / \mathrm{L}$ & 20.0 & 15.0 & 15.0 & - & - \\
\hline $\mathrm{CuCl}_{2} \cdot 2 \mathrm{H}_{2} \mathrm{O}$ & $\mathrm{mg} / \mathrm{L}$ & 2.0 & 1.5 & 1.5 & - & - \\
\hline $\mathrm{H}_{3} \mathrm{BO}_{3}$ & $\mathrm{mg} / \mathrm{L}$ & 4.0 & 3.0 & 3.0 & - & - \\
\hline $\mathrm{Na}_{2} \mathrm{MoO}_{4} \cdot 2 \mathrm{H}_{2} \mathrm{O}$ & $\mathrm{mg} / \mathrm{L}$ & 2.8 & 2.1 & 2.1 & - & - \\
\hline $\mathrm{Zn}\left(\mathrm{CH}_{3} \mathrm{COO}\right)_{2} \cdot \mathrm{H}_{2} \mathrm{O}$ & $\mathrm{mg} / \mathrm{L}$ & 33.8 & 33.8 & 33.8 & - & - \\
\hline EDTA & $\mathrm{mg} / \mathrm{L}$ & 18.8 & 14.1 & 14.1 & - & - \\
\hline Lactose & $\mathrm{g} / \mathrm{L}$ & - & 5.0 & - & - & - \\
\hline PPG 30\% & $\mathrm{mL} / \mathrm{L}$ & $1.0^{*}$ & - & - & - & - \\
\hline Thiamine & $\mathrm{mg} / \mathrm{L}$ & 45.0 & 45.0 & 45.0 & 45.0 & 45.0 \\
\hline Kanamycin & $\mathrm{mg} / \mathrm{L}$ & 30.0 & 50.0 & 50.0 & 50.0 & 50.0 \\
\hline
\end{tabular}

*Concentrations for glycerol and PPG $30 \%$ in bioreactor cultivation; LBM, modified LB medium, in which tryptone was replaced by soy peptone; $L B M S$, LBM supplemented with salts to identify the most promising strategy to produce PspA4Pro in the $5 \mathrm{~L}$ bioreactor.

\section{Screening of production conditions in shake flasks: ClearColi vs. conventional E. coli BL21(DE3)}

ClearColi and conventional E. coli BL21(DE3) were cultivated in a defined medium with glycerol as a carbon source, at different temperatures, using lactose and/or IPTG as inducers. The results showed, for the first time, that ClearColi® BL21(DE3) cells were able to grow in this medium and produce PspA4Pro. The conventional E. coli cells showed around 30\% higher growth rates than ClearColi in a defined medium (Table S1 - Supplementary Material, $\mathrm{SM})$. For both cell types, faster growth at higher temperatures led to shorter cultivations (Fig. S1, SM) since less time was required to reach $\mathrm{OD} \sim 2.0$ and induce recombinant protein production.

In all the shake flask cultivations using a defined medium, the ClearColi cells achieved the same maximum product yields as the conventional $E$. coli BL21(DE3) cells (Table S2, SM, Fig. 2d-f), at $27^{\circ} \mathrm{C}$ and $37^{\circ} \mathrm{C}$, even though higher recombinant protein titers were generally obtained in the cultures with the conventional cells, compared to ClearColi (Fig. 2a-c, Table S2). When induced only by IPTG, the two cell types presented similar product yield profiles, while for induction with lactose, the endotoxinfree cells required a longer induction phase to produce as much recombinant protein as the conventional cells, at lower temperatures (Fig. 2e-f). At $27{ }^{\circ} \mathrm{C}$, for both cell lines, the use of IPTG always led to higher PspA4Pro yields and titers, compared to the use of lactose, considering a 6-h induction time. For both platforms, the highest PspA4Pro yields using defined medium were observed at $32{ }^{\circ} \mathrm{C}$, using $0.5 \mathrm{mM}$ IPTG and $2.5 \mathrm{~g} / \mathrm{L}$ lactose to start induction (Fig. 2d-f, Table S2).

\section{Bioreactor cultivation using ClearColi $^{\circledR}$ BL21 (DE3)}

As mentioned above, the production of PspA in conventional $E$. coli BL21(DE3) cells has already been investigated using stirred-tank and airlift bioreactors (Horta et al. 2012; Campani et al. 2016, 2017, 2019; Figueiredo et al. 2017; Benedini et al. 2020; Cardoso et al. 2020). However, to date, the cultivation of ClearColi ${ }^{\circledR}$ BL21(DE3) in bioreactors has 
$\checkmark \mathrm{CC}-\mathrm{C} \longrightarrow \mathrm{CC}-\mathrm{IPTG} \longrightarrow \mathrm{CC}-\mathrm{LAC} \rightarrow \nabla-\mathrm{CC}-\mathrm{IPTG}+\mathrm{LAC}--\square-\mathrm{CV}-0--\triangleright-\mathrm{CV}-\mathrm{IPTG}--\nabla-\mathrm{CV}-\mathrm{LAC}--<--\mathrm{CV}-\mathrm{IPTG}+\mathrm{LAC}$
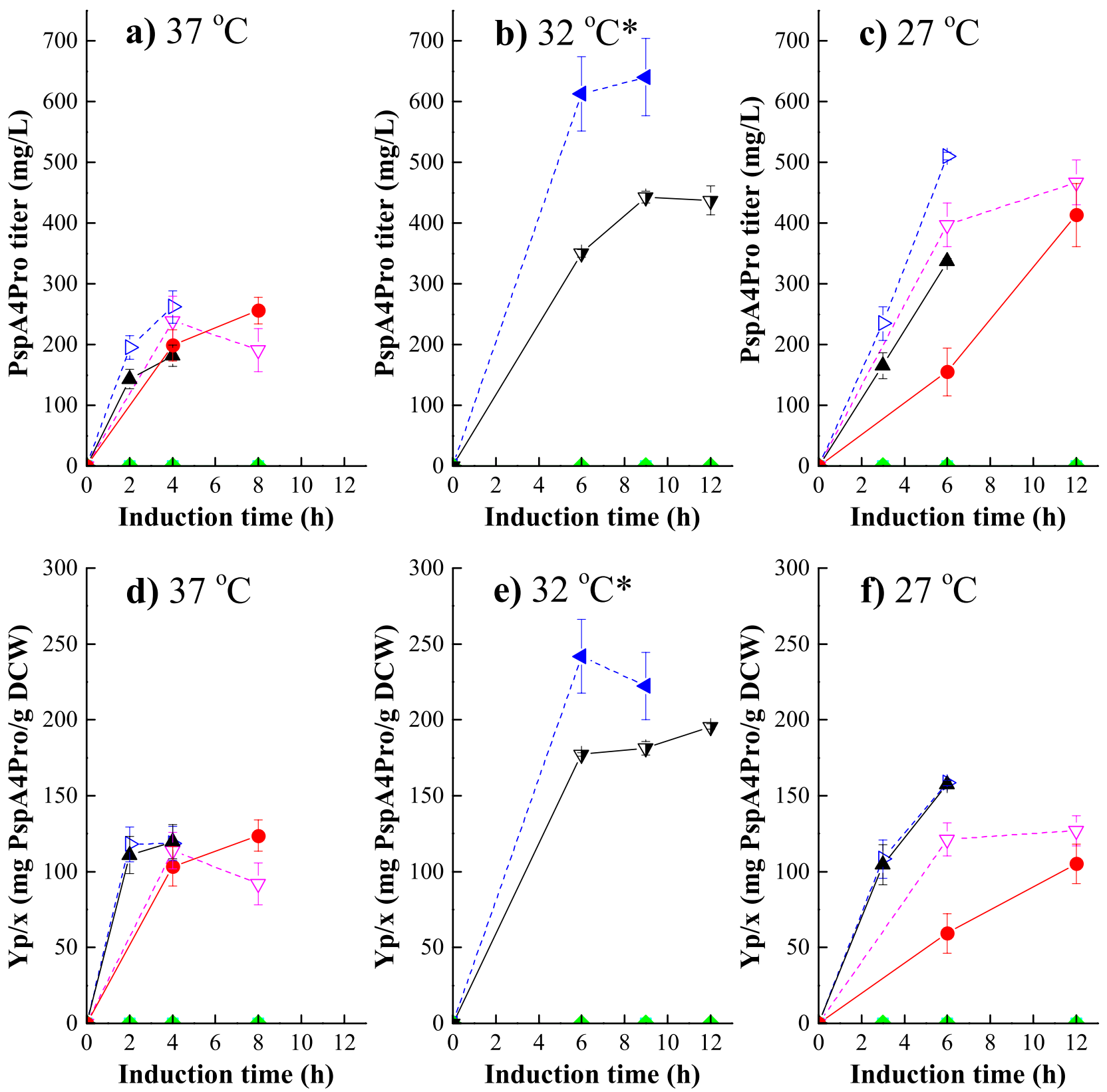

Fig. 2 Production of PspA4Pro in ClearColi® BL21(DE3) (CC) and conventional Escherichia coli BL21(DE3) cells (CV), using a defined medium with different temperatures and induction strategies, in shake flask experiments. Product titers at a $37{ }^{\circ} \mathrm{C}$, b $32{ }^{\circ} \mathrm{C}$, and c $27{ }^{\circ} \mathrm{C}$. Product yield $\left(\mathrm{Y}_{\mathrm{p} / \mathrm{x}}\right)$ at $\mathbf{d} 37^{\circ} \mathrm{C}$, e $32{ }^{\circ} \mathrm{C}$, and f $27^{\circ} \mathrm{C}$. IPTG,

not been addressed. Indeed, the performance of ClearColi ${ }^{\circledR}$ BL21(DE3) in a bioreactor culture is important to assess its potential as a platform for industrial-scale production of therapeutic proteins. Here, evaluation was made of the performance of ClearColi ${ }^{\circledR}$ BL21(DE3) using a 5-L stirred-tank bioreactor under the most promising conditions obtained in shake flask cultures with defined medium (induction with isopropyl- $\beta$-D-thiogalactopyranoside; LAC, lactose; 0 : without induction (control). *Induction conditions: pulse of $0.5 \mathrm{mM}$ IPTG plus $2.5 \mathrm{~g} / \mathrm{L}$ lactose $\left(32{ }^{\circ} \mathrm{C}\right)$; pulse of $1.0 \mathrm{mM}$ IPTG or $5.0 \mathrm{~g} / \mathrm{L}$ lactose $(27$ and $37^{\circ} \mathrm{C}$ )

$0.5 \mathrm{mM}$ IPTG plus $10 \mathrm{~g} / \mathrm{L}$ lactose, at $32{ }^{\circ} \mathrm{C}$ ). The biomass harvested from the bioreactor enabled purification and analysis of the structure and function of PspA4Pro produced by endotoxin-free cells, as described in the next section.

The specific growth rate of ClearColi in the bioreactor $\left(0.245 \pm 0.004 \mathrm{~h}^{-1}\right)$ was lower than obtained in the ClearColi shake flask experiments using a defined medium, at the same 
temperature $\left(32{ }^{\circ} \mathrm{C}\right)$, and equivalent to the value achieved at $27{ }^{\circ} \mathrm{C}$ (Table $\mathrm{S} 1$ ). This was probably due to the differences in bioreactor and shaker cultures, such as the addition of antifoam agent as well as the changes in the fluid dynamics due to the impellers in the former. As shown in Fig. 3, cell growth continued after induction, reaching a final cell density of $\sim 20 \mathrm{gDCW} / \mathrm{L}$, with low acetate accumulation. According to the Tukey test, PspA4Pro production per biomass, using ClearColi in the bioreactor, was stable throughout the induction phase $(137 \pm 14 \mathrm{mg} / \mathrm{gDCW})$, with a value lower than obtained using defined medium in shake flasks at $32{ }^{\circ} \mathrm{C}$ (Fig. 2e, Table S2). This yield was reached after $25.3 \mathrm{~h}$ of cultivation ( $3 \mathrm{~h}$ of induction), resulting in PspA4Pro productivity of $93 \pm 9.3 \mathrm{mg} /(\mathrm{L} \mathrm{h})$. Using conventional E. coli BL21(DE3) cells under similar cultivation conditions, but with induction using $1 \mathrm{mM}$ IPTG, Campani et al. (2017) achieved a PspA4Pro yield that was $20 \%$ lower $(118 \pm 11 \mathrm{mg} / \mathrm{gDCW})$, with the productivity of approximately $210 \mathrm{mg} /(\mathrm{L} \mathrm{h})$, due to the shorter cultivation process $(16.8 \mathrm{~h})$.

\section{PspA4Pro purification and quality assessment}

The ClearColi biomass harvested at the end of the bioreactor cultivation was used for purification of the PspA4Pro accumulated intracellularly (Figueiredo et al. 2017; Benedini et al. 2020) and evaluation of its biological function and secondary structure. The purification results were similar to data obtained previously when PspA4Pro was purified from conventional $E$. coli cells, but the last purification step (ion-exchange chromatography) could be omitted, because purity higher than $98 \%$ was reached after cryoprecipitation at pH 4.0 (Table 2).

PspA4Pro was not detected as inclusion bodies in any experiment carried out with ClearColi, indicating the correct folding of the protein during the synthesis (Fig. 4a). The CD spectra (Fig. 4b) showed that the PspA4Pro purified from ClearColi had practically the same secondary structure as the standard PspA4Pro. Both presented two typical valleys with minima at 208 and $222 \mathrm{~nm}$, similar to other CD spectra reported in the literature (Jedrzejas et al. 2000, 2001; Lamani et al. 2000; Haughney et al. 2013; Cardoso et al. 2020). Furthermore, the PspA4Pro purified from ClearColi showed a similar profile of lactoferrin binding as standard PspA4Pro (Fig. 4c). The lactoferrin binding assay utilizes rabbit anti-PspA4Pro antibodies for color development, so specific antibodies recognized the PspA4Pro purified from ClearColi, demonstrating that protein antigenicity was also preserved.

\section{Influence of medium enrichment on PspA production}

In the previous result sections, it was shown that ClearColi® BL21(DE3) could grow and produce PspA4Pro, with the desired quality, when cultivated in a defined

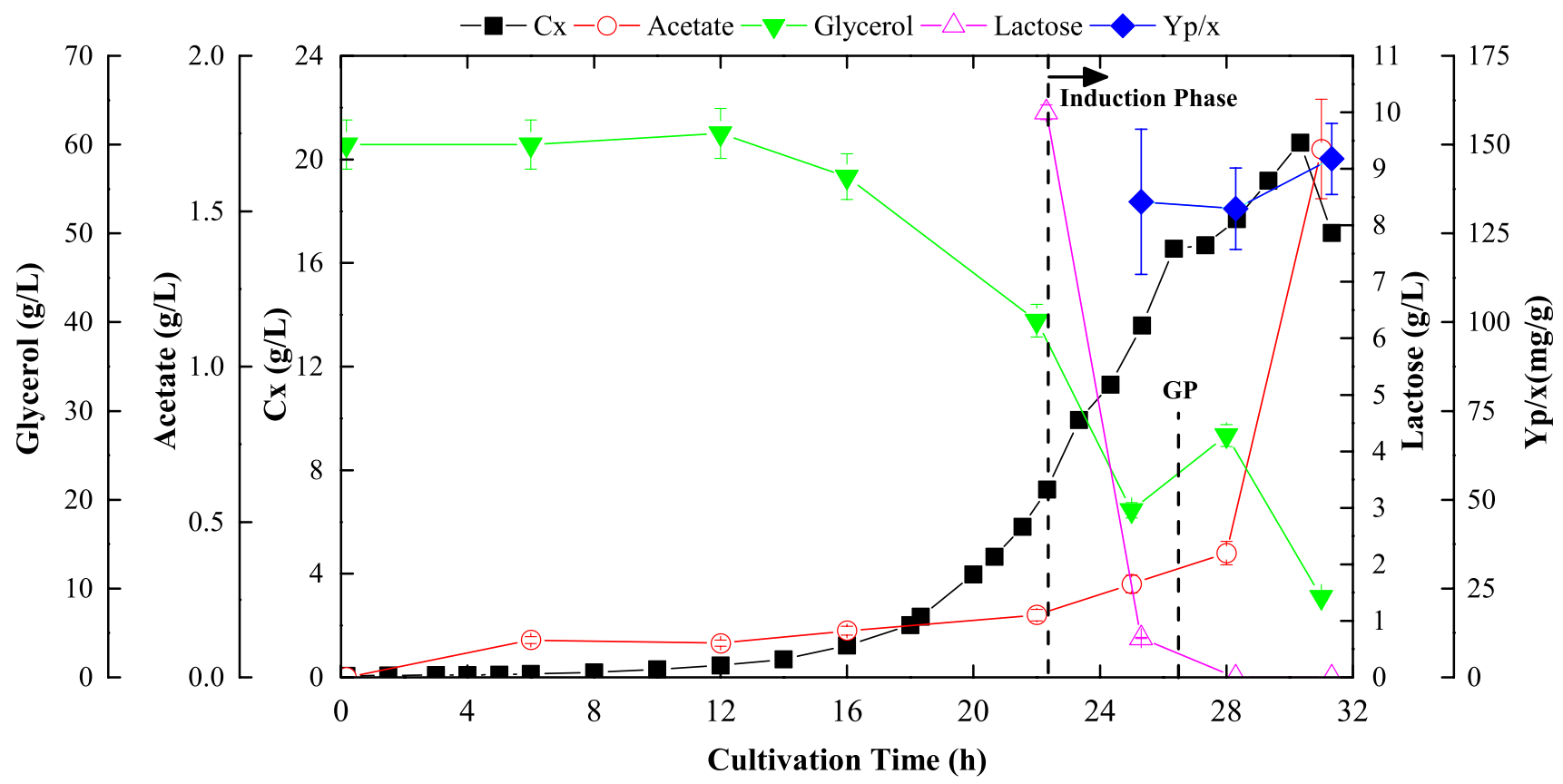

Fig. 3 Biomass formation, substrate consumption, and PspA4Pro production in the bioreactor. Conditions: defined medium at $32{ }^{\circ} \mathrm{C}$; induction by pulse ( $0.5 \mathrm{mM}$ IPTG plus $10 \mathrm{~g} / \mathrm{L}$ lactose $)$ at OD of $\sim 20$;
$300 \mathrm{~g} / \mathrm{L}$ glycerol pulse (GP) added to avoid carbon source depletion. $\mathrm{C}_{\mathrm{X}}$, Biomass concentration; $\mathrm{Y}_{\mathrm{p} / \mathrm{x}}$, product yield 
Table 2 Purification of PspA4Pro from ClearColi® BL21(DE3) cells. Italic superscript letters represent Tukey test indexes (95\% confidence level) for each variable (columns) at the end of the purification steps.
In each column, different letters mean experiments with statistically different results

\begin{tabular}{|c|c|c|c|c|c|c|c|}
\hline Platform & Purification step & Purity (\%) & PspA4Pro (g) & Global recovery (\%) & Step recovery $(\%)$ & $\begin{array}{l}\text { Purifica- } \\
\text { tion factor } \\
\text { (global) }\end{array}$ & $\begin{array}{l}\text { Purification factor } \\
\text { (step) }\end{array}$ \\
\hline \multirow[t]{5}{*}{$\mathrm{CC}$} & Cell lysate & $43.00 \pm 5.21^{a}$ & $6.90 \pm 0.83^{b}$ & $100.0 \pm 0.0^{d}$ & $100.0 \pm 0.0^{b}$ & $1.00 \pm 0.00^{a}$ & $1.00 \pm 0.00^{a}$ \\
\hline & Clarified cell extract & $56.80 \pm 8.02^{a, b}$ & $7.10 \pm 0.85^{b}$ & $102.9 \pm 14.8^{c, d}$ & $102.9 \pm 14.8^{b}$ & $1.30 \pm 0.07^{a}$ & $1.30 \pm 0.07^{a}$ \\
\hline & Q-Sepharose & $78.30 \pm 12.93^{b, c}$ & $1.90 \pm 0.12^{a}$ & $28.2 \pm 2.1^{a}$ & $27.4 \pm 6.1^{a}$ & $1.80 \pm 0.41^{a, b}$ & $1.40 \pm 0.37^{a, b}$ \\
\hline & Cryosupernatant & $98.30 \pm 5.16^{c}$ & $1.70 \pm 0.09^{a}$ & $25.3 \pm 4.7^{a}$ & $90.0 \pm 27.4^{a, b}$ & $2.30 \pm 0.25^{b}$ & $1.30 \pm 0.19^{a}$ \\
\hline & SP-Sepharose & $98.00 \pm 0.36^{c}$ & $1.60 \pm 0.01^{a}$ & $23.5 \pm 1.7^{a}$ & $92.6 \pm 15.6^{b}$ & $2.30 \pm 0.27^{b}$ & $1.00 \pm 0.05^{a}$ \\
\hline \multirow[t]{5}{*}{$\mathrm{CV}^{*}$} & Cell lysate & $33.40 \pm 4.05^{a}$ & $2.86 \pm 1.75^{a, b}$ & $100.0 \pm 0.0^{d}$ & $100.0 \pm 0.0^{b}$ & $1.00 \pm 0.00^{a}$ & $1.00 \pm 0.00^{a}$ \\
\hline & Clarified cell extract & $50.36 \pm 7.11^{a, b}$ & $2.67 \pm 1.87^{a, b}$ & $92.3 \pm 13.3^{c, d}$ & $92.3 \pm 13.3^{b}$ & $1.57 \pm 0.08^{a}$ & $1.57 \pm 0.08^{a, b}$ \\
\hline & Q-Sepharose & $65.20 \pm 10.77^{a, b}$ & $1.78 \pm 1.08^{a}$ & $62.0 \pm 4.7^{b}$ & $69.3 \pm 15.4^{a, b}$ & $2.06 \pm 0.47^{a, b}$ & $1.32 \pm 0.35^{b}$ \\
\hline & Cryosupernatant & $93.70 \pm 4.92^{c}$ & $1.39 \pm 0.99^{a}$ & $47.8 \pm 8.9^{a, b}$ & $82.7 \pm 25.2^{\mathrm{a}, \mathrm{b}}$ & $2.95 \pm 0.32^{b}$ & $1.30 \pm 0.19^{a}$ \\
\hline & SP-Sepharose & $97.80 \pm 0.3^{c}$ & $1.00 \pm 0.58^{a}$ & $35.3 \pm 2.5^{a}$ & $75.3 \pm 12.7^{a, b}$ & $2.96 \pm 0.35^{b}$ & $1.05 \pm 0.05^{a}$ \\
\hline
\end{tabular}

*Figueiredo et al. (2017)

medium. Other studies have highlighted the effects of medium composition on biomass and recombinant protein production by recombinant $E$. coli cells (Lee 1996; Zhang and Greasham 1999; Danquah and Forde 2007; Fong and Wood 2010; Cardoso et al. 2020). To date, the influence of the culture medium on PspA4Pro production by ClearColi ${ }^{\circledR}$ BL21(DE3) cultivated using different induction strategies has not been properly addressed. Therefore, shake cultivations were performed using different complex media (Table 1) based on peptone from different sources, with supplementations of salts, together with evaluation of the effect of the type and concentration of inducer, as described in "Experimental strategy." For a preliminary comparison of the complex medium formulations, all the experiments were carried out at $32{ }^{\circ} \mathrm{C}$, which was the temperature that led to the highest PspA4Pro yields in ClearColi cultures using a defined medium.

The LBMS medium was clearly superior to the LBM, LB, and auto-induction formulations, in terms of PspA4Pro yield and titer (Fig. 5b and e, Table S2), as well as productivity (Table 3). Hence, the addition of salts and glycerol to standard LB medium (Table 1) improved PspA4Pro production, while the use of soy peptone in the LBM formulation led to better results than with the tryptone present in LB (Fig. 5b and e, Tables 3 and S2). Protein production and productivity were also influenced by the concentration of IPTG employed. Induction with $0.5 \mathrm{mM}$ IPTG in the LBMS and LBM cultures led to higher PspA4Pro titers and yields, compared to the corresponding cultures induced with $1.0 \mathrm{mM}$ IPTG (Fig. 5b and e, Table S2), leading to higher productivities (Table 3). Interestingly, the control experiments using ClearColi cells in LBMS medium showed substantial PspA4Pro production (Fig. 5b and e, Tables 3 and S2), despite the fact that neither IPTG nor lactose was added in these experiments, suggesting the occurrence of unintended induction (Studier 2005).

Based on these results, the LBMS medium was chosen for further investigation of the influence of temperature on the induction strategy using a complex medium, and additional shake flask experiments were carried out using LBMS medium at 27 and $37^{\circ} \mathrm{C}$ (Fig. 5, Tables 3 and S2). Similar to the ClearColi shaker cultivations using the defined medium presented above, the use of LBMS medium and induction with a pulse of IPTG led to fast and high recombinant protein production, respectively, at 37 and $27^{\circ} \mathrm{C}$, for induction times of 4 and 8 h, respectively (Fig. $5 \mathrm{~d}$ and f, Table S2), as well as high productivities (Fig. 5a and c, Table 3). The addition of a pulse of lactose in the LBMS medium resulted in good induction performance, at the highest temperature of $37^{\circ} \mathrm{C}$, in terms of product yield (over $190 \mathrm{mg} / \mathrm{gDCW}$; Fig. $5 \mathrm{~d}$ and e, Table S2), titer ( $400 \mathrm{mg} / \mathrm{L}$; Fig. $5 \mathrm{a}$ and b, Table S2), and productivity ( $32 \mathrm{mg} /(\mathrm{L} \mathrm{h})$; Table 3$)$. As shown in Fig. 5, a clear correlation between cultivation temperature and recombinant protein production, which was observed using a defined medium, was not identified for the complex medium cultures. In general, increasing maximum PspA4Pro titers were related to longer induction times, while PspA4Pro productivities increased with temperature, when lactose was used for induction (Table 3).

The ClearColi cell growth profiles observed for the different strategies showed similar trends for the LBMS and defined media, with lower temperatures leading to higher OD (Figs. S1 and S2, Table S2, SM). The highest OD values $(\sim 17.0)$ were obtained in the control experiments (without induction) at $27{ }^{\circ} \mathrm{C}$, for both LBMS and defined media, while the lowest $\mathrm{OD}$ value $(\sim 3.0)$ among all the cultivations was observed for LB. As expected, high ClearColispecific growth rates occurred in the complex media, with 

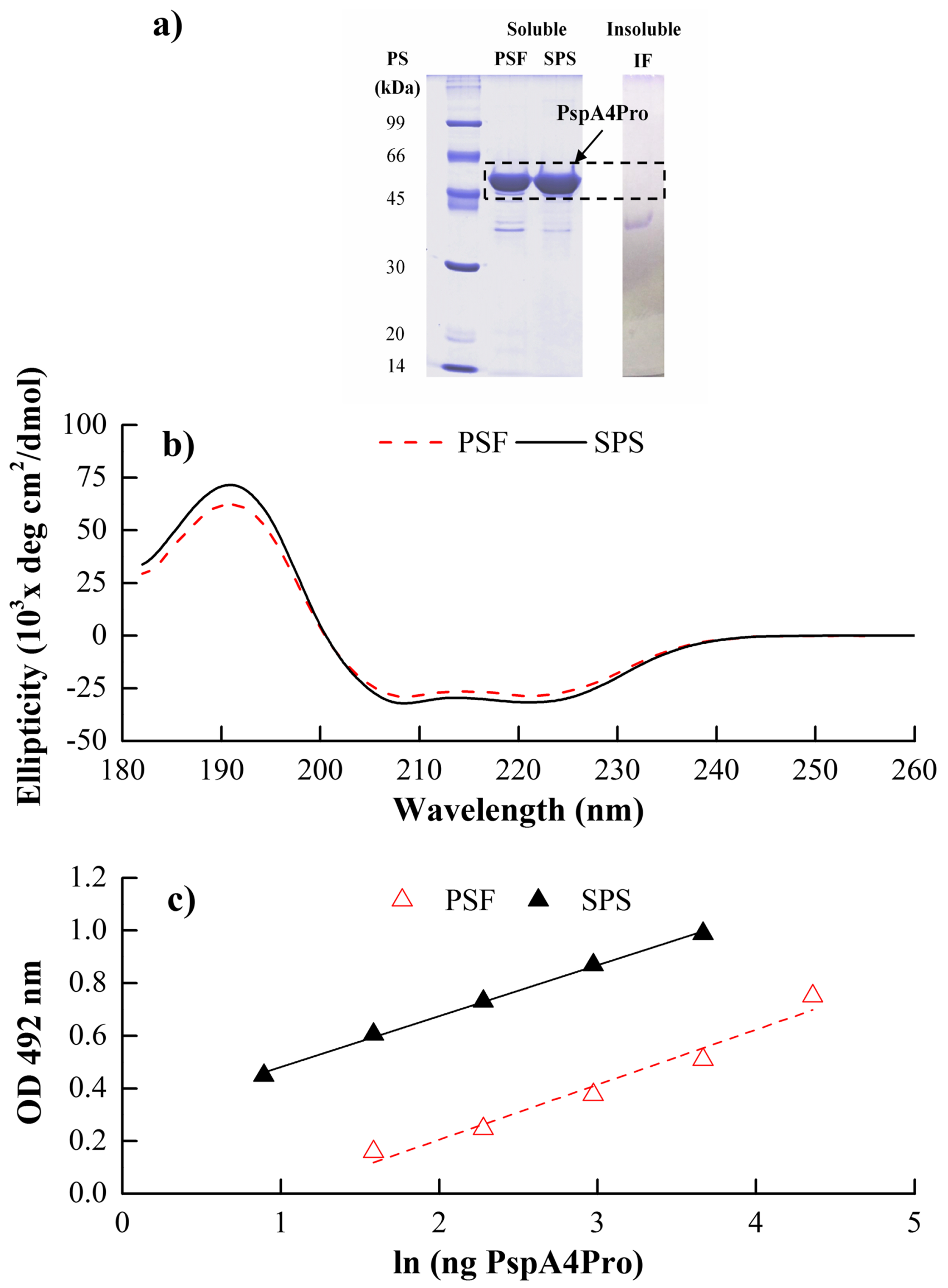
4Fig. 4 Quality of PspA4Pro obtained from biomass harvested in the bioreactor culture of ClearColi® BL21(DE3). a SDS-PAGE of purified cell extract and cell lysate; b circular dichroism (CD) spectra; c lactoferrin binding assay. PSF, purified soluble fraction from ClearColi cells; PS, protein standard; SPS, standard PspA4Pro sample; IF, an insoluble fraction of ClearColi cells

the cultivations using LBMS being 30-57\% faster than with defined medium, for the same cultivation temperatures (Table S1). The cultivation temperature had an important influence on the ClearColi growth rates, which decreased by around $30 \%$ when the temperatures were reduced by $5^{\circ} \mathrm{C}$ in the defined and LBMS medium cultivations.

\section{Discussion}

ClearColi ${ }^{\circledR}$ BL21(DE3) is an Escherichia coli BL21(DE3) strain with seven genetic deletions ( $m s b A 148, \Delta g u t Q$, $\Delta k d s D, \Delta l p x M, \Delta p a g P, \Delta l p x P$, and $\Delta e p t A)$, resulting in competent cells with a modified lipid $\mathrm{A}\left(\mathrm{IV}_{\mathrm{A}}\right)$ that does not cause an endotoxin response in human cells (Lucigen 2016). This modification may permit simpler and less expensive downstream processing, but the genetic modifications might also hamper recombinant protein production, compared to conventional E. coli BL21(DE3). Hence, it is important to evaluate the effects of different upstream process conditions on the production of recombinant proteins in ClearColi cultivations, in order to obtain products that are both reliable and cost-effective. In the present work, it was demonstrated that ClearColi@ BL21(DE3) cells could produce PspA4Pro, a promising recombinant protein candidate for use in new pneumococcal vaccines (Moreno et al. 2010; Horta et al. 2014; Campani et al. 2016, 2017, 2019; Figueiredo et al. 2017; Benedini et al. 2020; Cardoso et al. 2020). The evaluation was made of the effects of different process parameters including temperature, induction (type and concentration of inducer), and growth medium, as well as PspA4Pro production in 5 L bioreactor, using ClearColi ${ }^{\circledR}$ BL21(DE3). The ClearColi cells were able to produce PspA4Pro under all the conditions evaluated. Some relevant issues are discussed in the following sections.

\section{Influence of the medium on recombinant protein production by ClearColiø ${ }^{\text {BL21 (DE3) }}$}

To date, most of the studies with ClearColi ${ }^{\circledR}$ BL21(DE3) have employed submerged cultures with LB medium, in order to produce recombinant proteins in accordance with the recommendations of Lucigen (Lucigen 2016). The LB medium is a widely used rich broth that allows the growth of $E$. coli in an environment with controlled temperature, $\mathrm{pH}$, and oxygen supply, up to a cell density of approximately
$1 \mathrm{gDCW} / \mathrm{L}$ (Shiloach and Fass 2005). A few studies with ClearColi have used other complex media, such as Terrific Broth (TB) (Wilding et al. 2019a), 2xYT (Planesse et al. 2015; Abdellrazeq et al. 2019; Wilding et al. 2019a), and auto-induction (Hunt et al. 2019). Only one study was found where ClearColi was cultured in a mineral medium (Ran et al. 2019). The type of medium is an important factor affecting biomass formation and recombinant protein production (Zhang and Greasham 1999). Nevertheless, only Wilding et al. (2019a) provided an evaluation of ClearColi growth using three complex media (LB, 2xYT, and TB), where the use of TB led to the fastest growth rate $\left(0.72 \pm 0.12 \mathrm{~h}^{-1}\right)$. In comparison with defined media, the use of complex media generally leads to higher protein and biomass productivities in cultivations of prokaryotes (Lee 1996; Kim and Kim 2017). The present results showed that the complex medium components favored PspA4Pro yields, titers, and growth rates in the ClearColi cultivations. However, the maximum biomass formation in a culture was clearly related to the amount of the main carbon source provided during the experiments.

The presence of peptone and yeast extract is associated with increasing biomass and protein productivities (Studier 2005 ) since such formulations usually include amino acids and peptides, which are easily assimilated by the cells, interfering in growth rates (Cleland et al., 2007). Peptones may also contain carbohydrates which may be used as carbon and energy source for the heterotrophic microorganisms (Shuler and Kargi, 2002). Specifically, the type of peptone may affect recombinant protein production. Here, the results showed that soy peptone provided better biomass growth and PspA4Pro titers and yields in ClearColi cultures, compared to tryptone, in tests under the same process conditions, using LBM and LB media, respectively. Using soy peptone, the ClearColi cells were also able to grow and produce PspA4Pro in an auto-induction medium, which could be a promising strategy for the production of other recombinant proteins in studies at the shake flask scale. Auto-induction medium is highly recommended because it allows simplified control and operation, while providing higher protein production (Studier 2005; Hunt et al. 2019). Hunt et al. (2019), who obtained high expression of crisantaspase in ClearColi using an auto-induction medium, recommended this medium for cell-free protein synthesis (CFPS). The standard LB medium widely used in most of the studies involving ClearColi deserves special attention. The results showed that the recombinant protein production yield was drastically reduced when the LB medium was used. Hence, this formulation is not recommended, even in preliminary studies of heterologous protein production, since its use could lead to misleading results.

Some studies employing ClearColi® BL21(DE3) cells have used additives during the cultivations: $\mathrm{NaCl}$ to evaluate 


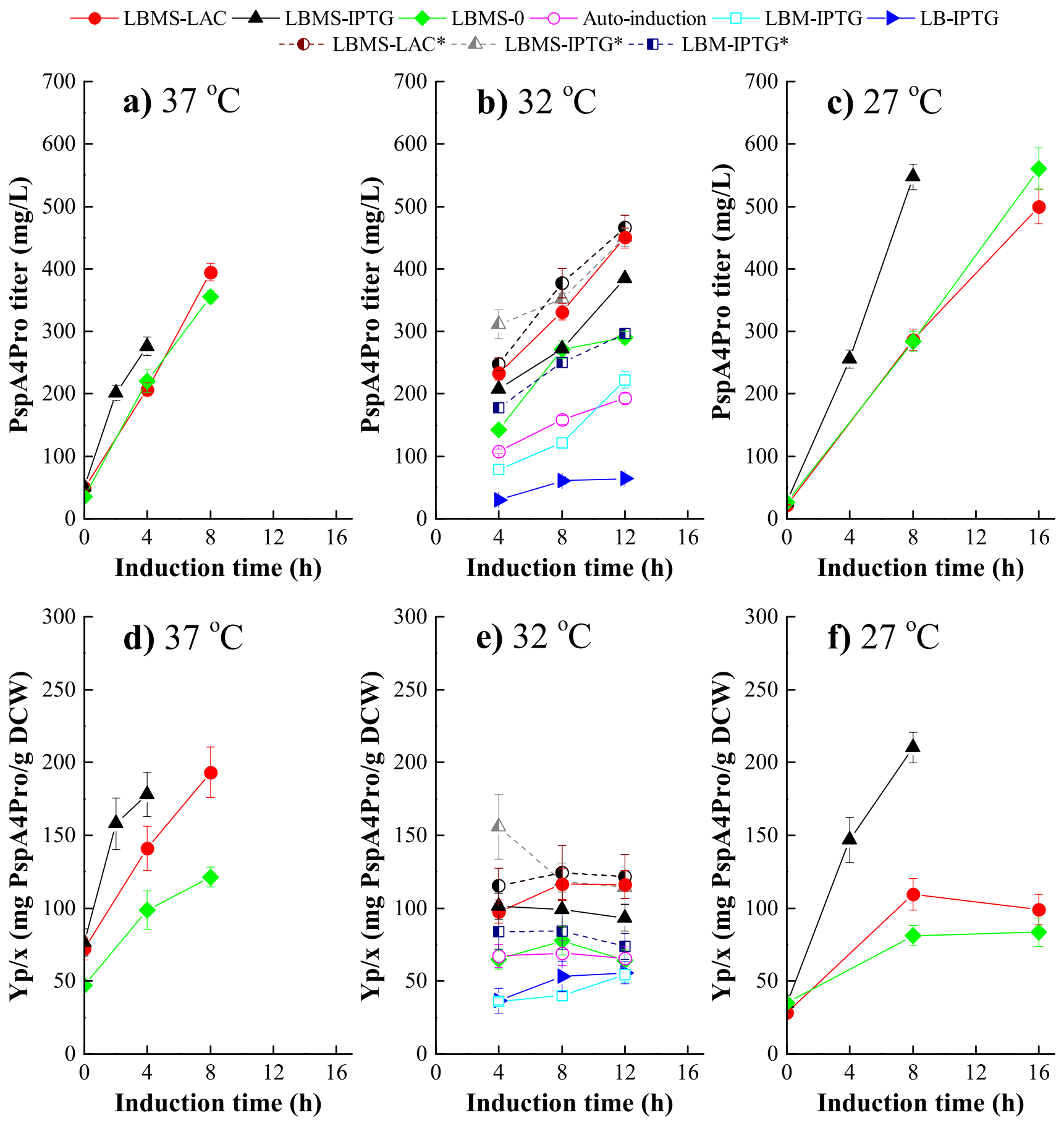

Fig. 5 Production of PspA4Pro for ClearColi ${ }^{\circledR}$ BL21(DE3) (CC) cultivation using a complex medium in shake flask experiments at different temperatures and with different induction strategies. Product titers at a $37{ }^{\circ} \mathrm{C}$, b $32{ }^{\circ} \mathrm{C}$, and c $27{ }^{\circ} \mathrm{C}$. Product yields $\left(\mathrm{Y}_{\mathrm{p} / \mathrm{x}}\right)$ at $\mathbf{d ~} 37^{\circ} \mathrm{C}$, e
$32{ }^{\circ} \mathrm{C}$, and $\mathbf{f} 27^{\circ} \mathrm{C}$. IPTG, isopropyl- $\beta$-D-thiogalactopyranoside; LAC, lactose; 0: without induction (control). Induction conditions: pulse of $1.0 \mathrm{mM}$ IPTG or $5.0 \mathrm{~g} / \mathrm{L}$ lactose $\left(27,32\right.$, and $\left.37^{\circ} \mathrm{C}\right)$ or $0.5 \mathrm{mM}$ IPTG or $2.5 \mathrm{~g} / \mathrm{L}$ lactose $\left(32^{\circ} \mathrm{C}\right.$, indicated by “*”) osmolarity and ionic strength effects (Wilding et al. 2019a); NaHS, HEPES, and glutathione (GSH) to improve protein solubility and expression (Ueda et al. 2016); glucose as a carbon source to inhibit transcription by the lac promoter and to prevent leaky expression (Liang et al. 2015; Ueda et al. 2016; González-Miro et al. 2017; Ran et al. 2019); and mercaptoethanol (Song et al. 2019). However, only Ueda et al. (2016) and Wilding et al. (2019a) investigated the ways in which the additives affected the ClearColi cultures. Ueda et al. (2016) concluded that $5 \mathrm{mM} \mathrm{GSH}$ and $100 \mu \mathrm{M}$ 
Table 3 PspA4Pro maximum productivities and the corresponding induction and cultivation times during the shake flask experiments

\begin{tabular}{|c|c|c|c|c|c|}
\hline Platform & $\mathrm{T}\left({ }^{\circ} \mathrm{C}\right)$ & Medium (inducer) & $\mathrm{P}_{\mathrm{P}}^{\max }(\mathrm{mg} /(\mathrm{L} \mathrm{h}))$ & $\mathrm{t}_{\mathrm{I}}(\mathrm{h})$ & $\mathrm{t}_{\mathrm{C}}(\mathrm{h})$ \\
\hline \multirow[t]{5}{*}{$\mathrm{CV}$} & \multirow[t]{2}{*}{37} & Defined (1.0 mM IPTG) & $28 \pm 2^{f, g}$ & 2 & 7 \\
\hline & & $(5.0 \mathrm{~g} / \mathrm{L}$ lactose $)$ & $24 \pm 3^{e, f}$ & 4 & 9 \\
\hline & 32 & Defined $(0.5 \mathrm{mM}$ IPTG $+2.5 \mathrm{~g} / \mathrm{L}$ lactose $)$ & $51 \pm 4^{h}$ & 6 & 12 \\
\hline & \multirow[t]{2}{*}{27} & Defined (1.0 mM IPTG) & $31 \pm 0^{g}$ & 6 & 15 \\
\hline & & $(5.0 \mathrm{~g} / \mathrm{L}$ lactose $)$ & $27 \pm 2^{f, g}$ & 6 & 13 \\
\hline \multirow[t]{20}{*}{$\mathrm{CC}$} & \multirow[t]{5}{*}{37} & Defined (1.0 mM IPTG) & $18 \pm 1^{c, d}$ & 2 & 9 \\
\hline & & $(5.0 \mathrm{~g} / \mathrm{L}$ lactose $)$ & $21 \pm 1^{b, c}$ & 4 & 11 \\
\hline & & LBMS (control) & $28 \pm 1^{f}$ & 4 & 8 \\
\hline & & (1.0 mM IPTG) & $38 \pm 1^{g}$ & 2 & 6 \\
\hline & & $(5.0 \mathrm{~g} / \mathrm{L}$ lactose $)$ & $32 \pm 1^{g}$ & 8 & 12 \\
\hline & \multirow[t]{10}{*}{32} & Defined (0.5 mM IPTG +2.5 g/L lactose) & $25 \pm 0^{g}$ & 6 & 14 \\
\hline & & LBMS (control) & $17 \pm 1^{d}$ & 4 & 10 \\
\hline & & (0.5 mM IPTG) & $26 \pm 1^{f, g}$ & 4 & 10 \\
\hline & & (1.0 mM IPTG) & $19 \pm 1^{d}$ & 4 & 11 \\
\hline & & $(2.5 \mathrm{~g} / \mathrm{L}$ lactose $)$ & $27 \pm 1^{e, f}$ & 4 & 10 \\
\hline & & $(5.0 \mathrm{~g} / \mathrm{L}$ lactose $)$ & $23 \pm 1^{e}$ & 4 & 11 \\
\hline & & LBM (0.5 mM IPTG) & $23 \pm 1^{c, d}$ & 4 & 11 \\
\hline & & (1.0 mM IPTG) & $9 \pm 1^{b}$ & 4 & 11 \\
\hline & & LB (1.0 mM IPTG) & $4 \pm 1^{a}$ & 4 & 11 \\
\hline & & Auto-induction $(5.0 \mathrm{~g} / \mathrm{L}$ lactose $)$ & $11 \pm 0^{b}$ & 4 & 10 \\
\hline & \multirow[t]{5}{*}{27} & Defined (1.0 mM IPTG) & $19 \pm 0^{d}$ & 6 & 15 \\
\hline & & (5.0 g/L lactose) & $17 \pm 2^{c, d}$ & 6 & 13 \\
\hline & & LBMS (control) & $23 \pm 1^{e}$ & 16 & 24 \\
\hline & & (1.0 mM IPTG) & $34 \pm 1^{g}$ & 8 & 16 \\
\hline & & $(5.0 \mathrm{~g} / \mathrm{L}$ lactose $)$ & $19 \pm 1^{d, e}$ & 8 & 16 \\
\hline
\end{tabular}

Italic superscript letters: Tukey test indexes (95\% confidence level). Different letters mean experiments with statistically different results
$\mathrm{NaHS}$, at $30^{\circ} \mathrm{C}$, was the best combination for expression of soluble human stem factor (hSCF), while Wilding et al. (2019a) observed that increasing the $\mathrm{NaCl}$ concentration above $5 \mathrm{~g} / \mathrm{L}$ did not significantly improve cell growth rates and densities. Here, the investigation was made of the effect of the salts present in auto-induction medium, comparing the results for the LBMS (with salt addition) and LBM (without salt addition) media, under the same process conditions. It was evident that the salts intensified PspA4Pro production since the better performance was achieved using the LBMS medium, compared to LBM.

Although research with ClearColi® BL21(DE3) has mainly focused on the use of complex media, defined media should be considered for the production of recombinant proteins, especially when therapeutical products are the target. This fact is because their known composition enables the concentrations of individual components to be followed, facilitating bioreactor control and complying with good manufacturing practice (GMP) guidelines (Zhang and Greasham 1999). The results obtained here demonstrated that ClearColi ${ }^{\circledR}$ BL21(DE3) cultures in a defined medium were able to produce PspA4Pro, presenting performance similar to that of conventional E. coli cells (discussed below). In addition, the ClearColi cells reached the same maximum biomass concentration as in the best complex medium investigated (LBMS), although a longer time was required for the defined medium culture, compared to LBMS, due to lower growth rates at all the cultivation temperatures tested.

\section{Influence of temperature on recombinant protein production in ClearColi ${ }^{\circledR}$ BL21(DE3)}

The cultivation temperature is an important operational condition that can affect $E$. coli cultures and soluble recombinant protein production (Cardoso et al. 2020). To the best of our knowledge, only three studies have mentioned the effect of temperature on protein production using ClearColi ${ }^{\circledR}$ BL21(DE3) cells. Ueda et al. (2016) found no improvements in hSCF expression and solubility at 16 and $25{ }^{\circ} \mathrm{C}$, with $30{ }^{\circ} \mathrm{C}$ being the best temperature. Segovia-Trinidad et al. (2021) concluded that the induction temperature did not increase soluble constitutive-active human-Smad8 (hcS$\operatorname{mad} 8)$, but no details of the temperature range and other 
supporting data were provided. Nguyen et al. (2021) demonstrated that the human granulocyte-macrophage colonystimulating factor (hGM-CSF) was overexpressed with induction at $30{ }^{\circ} \mathrm{C}$, compared to the use of temperatures of 37 and $18{ }^{\circ} \mathrm{C}$. Most of the papers addressing ClearColi ${ }^{\circledR}$ BL21(DE3) cultures have used the temperature recommended by Lucigen $\left(37^{\circ} \mathrm{C}\right)$ or have reproduced successful strategies for other $E$. coli strains, in order to produce target proteins using ClearColi.

Evaluation of the influence of temperature on PspA4Pro production using ClearColi ${ }^{\circledR}$ BL21(DE3) employed shake flask experiments at 27,32 , and $37^{\circ} \mathrm{C}$. These temperatures were selected on the basis that this recombinant protein from E. coli BL21(DE3) cells has always been found to be soluble in this temperature range (Campani et al. 2016, 2017, 2019; Figueiredo et al. 2017; Benedini et al. 2020; Cardoso et al. 2020).

The analyses found no evidence of inclusion body formation at any cultivation temperature. Despite being lower than for conventional E. coli, the growth rates of the ClearColi cells in defined and LBMS media increased between 27 and $32{ }^{\circ} \mathrm{C}$ and approximately doubled between 27 and $37^{\circ} \mathrm{C}$. Considering PspA4Pro production, in the defined medium experiments, the best PspA4Pro yield, titer, and productivity results were obtained at $32{ }^{\circ} \mathrm{C}$, as observed previously for conventional cells, probably due to a better balance of metabolic burden and biomass production (Donovan et al. 1996; Campani et al. 2017; Cardoso et al. 2020). Interestingly, in the experiments with LBMS, the temperature had different effects on PspA4Pro yield, titer, and productivity, depending on the induction conditions. When IPTG was used as an inducer, the maximum yield, titer, and productivity occurred at $27^{\circ} \mathrm{C}$. On the other hand, for induction using lactose, as well as in unintended induction in the control experiments, the maximum titers occurred at $27^{\circ} \mathrm{C}$, while the maximum yields and productivities were observed at $37^{\circ} \mathrm{C}$. As already discussed above, complex medium formulations contain several nutrients that can boost cell metabolism, in synergy with temperature changes.

\section{Induction strategy for ClearColi ${ }^{\circledR}$ BL21(DE3)}

The induction strategy plays an important role in recombinant protein production using $E$. coli cells. In addition to the induction temperature, discussed before, other factors such as the type of inducer, duration of induction, timing of induction, and inducer concentration can have important effects on the overexpression of recombinant proteins, in accordance with quality standards (Kaur et al. 2018; Cardoso et al. 2020). However, the most suitable induction strategy depends on the characteristics of the target recombinant protein, requiring investigation on a case-by-case basis (Cardoso et al. 2020). To date, most of the induction strategies for the production of recombinant proteins in ClearColi ${ }^{\circledR}$ BL21(DE3) cells have followed the recommendations provided by Lucigen (Lucigen 2016). In this procedure, induction is performed with an IPTG pulse in the mid-exponential phase $(0.6<\mathrm{OD}<0.8)$, during a period between 2 and $16 \mathrm{~h}$, with a final IPTG concentration from 0.4 to $1.0 \mathrm{mM}$. Several studies with ClearColi ${ }^{\circledR}$ BL21(DE3) have used alternative induction strategies (Liang et al. 2015; Watkins et al. 2017b, 2017a; Yoo et al. 2017; An et al. 2019; Hunt et al. 2019; Sankaran et al. 2019; Sankaran and del Campo 2019; Song et al. 2019; Wilding et al. 2019a, 2019b; Gnopo et al. 2020; Segovia-Trinidad et al. 2021). However, the effects of different induction modes (pulse or auto-induction), inducers, and IPTG and lactose concentrations in recombinant protein production using ClearColi have not previously been investigated in a single study.

The production of PspA4Pro in ClearColi ${ }^{\circledR}$ BL21(DE3) cells was firstly carried out using induction conditions similar to those that have been employed for conventional E. coli BL21(DE3) culture (da Silva et al. 2013; Cardoso et al. 2020). The induction was performed with a pulse that resulted in final concentrations of $1.0 \mathrm{mM}$ IPTG or $5.0 \mathrm{~g} / \mathrm{L}$ lactose, at OD 2.0 and it lasted between 2 and $16 \mathrm{~h}$, depending on the temperature. Under the conditions employed, a final concentration of $5.0 \mathrm{~g} / \mathrm{L}$ lactose resulted in the same maximum PspA4Pro titers and yields attained with $1.0 \mathrm{mM}$ IPTG. However, the ClearColi cultures showed lower recombinant protein productivity due to longer cultivation time when lactose was used as the inducer, as it also happens for recombinant $E$. coli strains in which the expression system is based on lac operon (Cardoso et al. 2020). The need to fully induce or activate lac permease synthesis for the transport of lactose can explain the delayed induction response in this expression system since IPTG transport does not depend on lac permease (Donovan et al., 1996).

There are few studies addressing the influence of inducer (lactose or IPTG) concentration on recombinant protein production by conventional $E$. coli BL21(DE3) cells under lac operon control (Einsfeldt et al. 2011; Lecina et al. 2013; Ferreira et al. 2018; Barros et al. 2021; Von den Eichen et al. 2021), but none for ClearColi ${ }^{\circledR}$ BL21(DE3) so far. Segovia-Trinidad et al. (2021) reported that other induction methods and inducer concentrations did not increase soluble production of constitutive-active human-Smad8, but they did not detail their investigation nor present the results. In the present work, reducing the final inducer concentrations by half was demonstrated to be effective for ClearColi cells: $2.5 \mathrm{~g} / \mathrm{L}$ lactose produced as much as recombinant protein as in cultivations with induction using $5.0 \mathrm{~g} / \mathrm{L}$ lactose. On the other hand, PspA4Pro production was increased using $0.5 \mathrm{mM}$ IPTG since, in excess, IPTG has been reported to negatively affect $E$. coli cell growth and protein expression (Donovan et al. 1996; Einsfeldt et al. 2011). 
Interestingly, the induction of ClearColi ${ }^{\circledR}$ BL21(DE3) cultures by a pulse of lactose led to higher levels of PspA4Pro than obtained in auto-induction cultivations, even though the final concentrations of lactose were the same in these cultivations. The same behavior was already observed for conventional $E$. coli BL21(DE3) cells and attributed to the earlier induction in auto-induction strategy, which triggered the so called "metabolic burden" related to heterologous protein production ( $\mathrm{Li}$ et al. 2006; Carneiro et al. 2013; da Silva et al. 2021) and restricted the allocation of cellular resources for biomass formation and other metabolic activities (da Silva et al. 2021). Nevertheless, these results did not preclude the use of auto-induction medium in ClearColi cultivations, especially considering that it simplifies the control, monitoring, and operation of cultures (Hunt et al. 2019).

Surprisingly, PspA4Pro production was evident in all the complex medium cultivations, even without the addition of lactose or IPTG, with high protein contents reached in all the control experiments using the LBMS medium. Grossman et al. (1998) have reported high-level recombinant protein expression in E. coli BL21(DE3) cultures using the complex medium in the absence of inducers. Studier (2005) attributed this unintended induction to the lack of a lac operon repressor, such as glucose, and/or the presence of trace amounts of lactose in the cultivation medium. In addition, non-metabolizable lactose analogs (Rao and Koirala 2014) or galactose (Xu et al., 2012) were reported to trigger the expression of the lac operon genes. Soy peptone used in LBMS medium formulation contains high levels of carbohydrates (Michiels et al. 2011), which are released during peptone manufacturing from soy protein concentrates. Therefore, galactose, trace amounts of lactose or lactose-analog carbohydrates arise as possible causes for the unintended PspA4pro production in ClearColi BL21(DE3) during control experiments in the LBMS medium formulation.

\section{ClearColi vs. conventional E. coli BL21(DE3) cells as platforms for recombinant protein production}

\section{Shake flask cultivations}

In the last years, there has been a substantial increase in the number of studies evaluating the use of ClearColi ${ }^{\circledR}$ BL21(DE3) cells for the production of endotoxin-free recombinant proteins and other products. However, the genetic modifications required to make ClearColi ${ }^{\circledR}$ BL21(DE3) cell endotoxin-free might not only play a role in reducing the specific growth rate (Mamat et al. 2015; Lucigen 2016), but also affect recombinant product yield, titer, and productivity. To date, only a few published papers have compared the production results for ClearColi ${ }^{\circledR} \mathrm{BL} 21(\mathrm{DE} 3)$ and E. coli BL21(DE3) cells. Ueda et al. (2016) reported that ClearColi produced substantially less recombinant human stem cell factor, compared to E. coli BL21(DE3), using a thioredoxin co-expression system, requiring the creation of a new expression system based on additions of GSH and NaHS to ensure feasibility. Wilding et al. (2019a) observed that CFPS production using ClearColi cells was equivalent to $20 \%$ of the product obtained in standard BL21(DE3) extracts, although adjustments of the medium and induction strategy could enable equivalence between ClearColi ${ }^{\circledR}$ BL21(DE3) and BL21 Star (DE3) cultures. Segovia-Trinidad et al. (2021) mentioned that the E. coli BL21(DE3) and E. coli Turner BL21(DE3) strains did not present higher soluble hcSmad8 production, compared to ClearColi. Other studies have found that the performance of ClearColi ${ }^{\circledR}$ BL21(DE3) exceeded that of conventional E. coli BL21(DE3) (Song et al. 2019; Nguyen et al. 2021), in addition to providing higher protein solubility (Nguyen et al. 2021).

Cultivations of ClearColi ${ }^{\circledR}$ BL21(DE3) and conventional E. coli BL21(DE3) cells were performed at 27, 32, and $37^{\circ} \mathrm{C}$, using a defined medium with IPTG or lactose as inducers to produce PspA4Pro. Considering statistical significance, with the exception of the cultures at $32{ }^{\circ} \mathrm{C}$, the two E. coli platforms showed the same performance in terms of maximum recombinant protein yield. The maximum PspA4Pro titers were equivalent when lactose was the inducer, while the ClearColi cells achieved lower values than conventional cells for cultures induced by IPTG. For ClearColi, longer induction periods acted to increase the expression level. The results obtained using defined medium demonstrated that ClearColi ${ }^{\circledR}$ BL21(DE3) could provide high PspA4Pro yield and titer values, even though the endotoxinfree cell cultivations frequently resulted in lower product productivity, compared to conventional E. coli BL21(DE3) cultivations. The lower specific growth rates of ClearColi, compared to conventional cells, played an important role in this since longer cultivation times directly influenced recombinant protein productivity.

\section{Scale-up and purification}

Scale-up of cultivations is usually a challenge in bioprocesses (Yang et al. 2007; Goldrick et al. 2020). Furthermore, it is important to evaluate newly developed recombinant protein production platforms under industrial operation conditions, in order to assess their full potentials as hosts in scaled up processes. To the best of our knowledge, up to now, there has been no publication addressing the cultivation of ClearColi ${ }^{\circledR}$ BL21(DE3) in bioreactors and using volumes larger than $2.0 \mathrm{~L}$. The results obtained here demonstrated that ClearColi ${ }^{\circledR}$ BL21(DE3) can not only grow to cell densities higher than those usually obtained in shake flasks, but also provide high protein yields. Under similar bioreactor conditions, the cultivation of conventional E. coli BL21(DE3) cells led to 50\% 
higher biomass concentration, 20\% lower PspA4Pro yield, and a cultivation time that was $10 \mathrm{~h}$ shorter, compared to ClearColi cultivation (Campani et al. 2017), resulting in 20\% higher PspA4Pro productivity. Other studies using shake flask cultivations found that ClearColi performed better than conventional E. coli, in terms of the yields of recombinant proteins (Song et al. 2019; Nguyen et al. 2021). Nevertheless, the low specific growth rate of ClearColi decreases upstream productivity, requiring new strategies to be developed with the aim of accelerating biomass formation. Following successful strategies for conventional E. coli BL21(DE3) bioreactor cultivations (Horta et al. 2012; Campani et al. 2016, 2017), the use of glycerol as the main carbon source was effective for avoiding acetate accumulation in the broth (acetate concentrations $<2 \mathrm{~g} / \mathrm{L}$ ) and, consequently, inhibition of the growth of ClearColi cells by this metabolite during the bioreactor cultivation. Additional studies considering aspects such as medium optimization, supplementation with additives, and the use of genetic engineering tools to create new strains could further improve bioreactor production conditions and the yields of recombinant proteins in ClearColi cultures.

The main advantages of ClearColi ${ }^{\circledR}$ BL21(DE3) have generally been associated with the possibility of performing simpler downstream processing in order to obtain endotoxin-free therapeutic heterologous proteins (Lucigen 2016) that meet the desired quality requirements (Mamat et al. 2015; Planesse et al. 2015; Ueda et al. 2016; Pooe et al. 2017; Viranaicken et al. 2017; Watkins et al. 2017b, 2017a; Hunt et al. 2019; Qiao et al. 2019; Wilding et al. 2019a). Some studies have reported better purification performance when recombinant proteins were produced using ClearColi ${ }^{\circledR}$ BL21(DE3). For example, Nguyen et al. (2021) achieved $98 \%$ purity after two conventional chromatography steps, with higher expression and higher solubility of hGM-CSF, compared to the use of conventional E. coli. Ueda et al. (2016) found that the characteristics of binding of the rhSCF produced in ClearColi ${ }^{\circledR}$ BL21(DE3) to the affinity resin were greatly improved, compared to the use of conventional E. coli BL21(DE3). In the present work, it was demonstrated that by applying purification protocols identical to those established for conventional E. coli (Figueiredo et al. 2017; Benedini et al. 2020; Cardoso et al. 2020), the use of ClearColi cells could provide PspA4Pro at 98\% purity, meeting the quality requirements, maintaining both the secondary structure and antigenicity of PspA4Pro. This is a promising preliminary result, with further improvements expected after updating and optimization of the purification protocols employed to process endotoxin-free cell extracts.

Supplementary Information The online version contains supplementary material available at https://doi.org/10.1007/s00253-022-11758-9.
Acknowledgements The authors thank Renan Minin de Mori for providing rabbit anti-PspA4Pro antibodies, Prof. Adilson José da Silva for recombinant plasmid pET37b(+)pspA4Pro insertion in ClearColi ${ }^{\circledR}$ BL21(DE3) cells and Kerry Ingredients and Flavours for donating the soy peptone $\mathrm{A} 2 \mathrm{C}$ used in the complex medium experiments.

Author contribution V.M.C., S.A.H.P., and T.C.Z. conceived and designed the research. V.M.C., S.A.H.P., and G.C. conducted upstream experiments and analyses. V.M.G. conducted purification runs and analyses. V.M.C. and T.C.Z. analyzed the data. V.M.C. wrote the manuscript. T.C.Z. and V.M.G. reviewed the manuscript. All authors read and approved the manuscript.

Funding Coordenação de Aperfeiçoamento de Pessoal de Nível Superior, Brazil (CAPES - Finance code 001) and São Paulo State Research Foundation (FAPESP, grants \#2015/10291-8 and \#2016/50413-8).

Data availability The datasets generated during and/or analyzed during the current study are available from the corresponding author on reasonable request.

Code availability Not applicable.

\section{Declarations}

Ethics approval Not applicable.

Consent to participate Not applicable.

Consent for publication Not applicable.

Conflict of interest The authors declare no competing interests.

\section{References}

Abdellrazeq GS, Elnaggar MM, Bannantine JP, Schneider DA, Souza CD, Hwang J, Mahmoud AHA, Hulubei V, Fry LM, Park KT, Davis WC (2019) A peptide-based vaccine for Mycobacterium avium subspecies paratuberculosis. Vaccine 37:2783-2790. https://doi.org/10.1016/j.vaccine.2019.04.040

Abdellrazeq GS, Fry LM, Elnaggar MM, Bannantine JP, Schneider DA, Chamberlin WM, Mahmoud AHA, Park KT, Hulubei V, Davis WC (2020) Simultaneous cognate epitope recognition by bovine CD4 and CD8 T cells is essential for primary expansion of antigen-specific cytotoxic T-cells following ex vivo stimulation with a candidate Mycobacterium avium subsp. paratuberculosis peptide vaccine. Vaccine 38:2016-2025. https://doi.org/10.1016/j. vaccine.2019.12.052

Abràmoff MD, Magalhães PJ, Ram SJ (2004) Image Processing with ImageJ. Biophotonics Int 11:36-42

An J, Kim SH, Hwang D, Lee KE, Kim MJ, Yang EG, Kim SY, Chung HS (2019) Caspase-4 disaggregates lipopolysaccharide micelles via LPS-CARD interaction. Sci Rep 9(1):826. https://doi.org/10. 1038/s41598-018-36811-4

Barros T, Brumano L, Freitas M, Pessoa Junior A, Parachin N, Magalhães PO (2021) Development of processes for recombinant L-asparaginase II production by Escherichia coli B121 (De3): from shaker to bioreactors. Pharmaceutics 13:1-15. https://doi. org/10.3390/pharmaceutics13010014

Benedini LJ, Figueiredo D, Cabrera-Crespo J, Gonçalves VM, Silva GG, Campani G, Zangirolami TC, Furlan FF (2020) Modeling and 
simulation of anion exchange chromatography for purification of proteins in complex mixtures. J Chromatogr 1613:460685. https:// doi.org/10.1016/j.chroma.2019.460685

Bong JH, Kim J, Lee GY, Park JH, Kim TH, Kang MJ, Pyun JC (2019) Fluorescence immunoassay of E. coli using anti-lipopolysaccharide antibodies isolated from human serum. Biosens Bioelectron 126:518-528. https://doi.org/10.1016/j.bios.2018.10.036

Bradford MM (1976) A rapid and sensitive method for the quantitation microgram quantities of protein utilizing the principle of proteindye binding. Anal Biochem 72:248-254. https://doi.org/10.1016/ 0003-2697(76)90527-3

Briles DE, Hollingshead S, Brooks-Walter A, Nabors GS, Ferguson L, Schilling M, Gravenstein S, Braun P, King J, Swift A (2000) The potential to use PspA and other pneumococcal proteins to elicit protection against pneumococcal infection. Vaccine 18:17071711. https://doi.org/10.1016/S0264-410X(99)00511-3

Campani G, Santos MP, Gonçalves G, Horta ACL, Badino AC, Giordano RDC, Maimoni V, Zangirolami TC (2016) Recombinant protein production by engineered Escherichia coli in a pressurized airlift bioreactor: a techno-economic analysis. Chem Eng Process Process Intensif 103:63-69. https://doi.org/10.1016/j.cep. 2015.10.020

Campani G, Silva GG, Zangirolami TC, Ribeiro MPA (2017) Recombinant Escherichia coli cultivation in a pressurized airlift bioreactor: assessment of the influence of temperature on oxygen transfer and uptake rates. Bioprocess Biosyst Eng 40:1621-1633. https://doi. org/10.1007/s00449-017-1818-7

Campani G, Ribeiro MPA, Zangirolami TC, Lima FV (2019) A hierarchical state estimation and control framework for monitoring and dissolved oxygen regulation in bioprocesses. Bioprocess Biosyst Eng 42:1467-1481. https://doi.org/10.1007/s00449-019-02143-4

Cardoso VM, Campani G, Santos MP, Silva GG, Pires MC, Gonçalves VM, de C. Giordano R, Sargo CR, Horta ACL, Zangirolami TC, (2020) Cost analysis based on bioreactor cultivation conditions: production of a soluble recombinant protein using Escherichia coli BL21(DE3). Biotechnol Reports 26:e0441. https://doi.org/ 10.1016/j.btre.2020.e00441

Carneiro S, Ferreira EC, Rocha I (2013) Metabolic responses to recombinant bioprocesses in Escherichia coli. J Biotechnol 164:396408. https://doi.org/10.1016/j.jbiotec.2012.08.026

Carratalá JV, Gifre-Renom L, Roca-Pinilla R, Villaverde A, Arís A, Garcia-Fruitós E, Sánchez JM, Ferrer-Miralles N (2021) Selecting subpopulations of high-quality protein conformers among conformational mixtures of recombinant bovine mmp-9 solubilized from inclusion bodies. Int J Mol Sci 22:1-15. https://doi.org/10. 3390/ijms22063020

Carvalho RJ, Cabrera-crespo J, Tanizaki MM, Gonçalves VM (2012) Development of production and purification processes of recombinant fragment of pneumococcal surface protein A in Escherichia coli using different carbon sources and chromatography sequences. Appl Microbiol Biotechnol 94:683-694. https://doi. org/10.1007/s00253-011-3649-9

Cleland D, Jastrzembski K, Stamenova E, Benson J, Catranis C, Emerson D, Beck B (2007) Growth characteristics of microorganisms on commercially available animal-free alternatives to tryptic soy medium. J Microbiol Methods 69:345-352. https://doi.org/10. 1016/j.mimet.2007.02.004

da Silva AJ, Horta ACL, Velez AM, Iemma MRC, Sargo CR, Giordano RLC, Novo MTM, Giordano RC, Zangirolami TC (2013) Nonconventional induction strategies for production of subunit swine erysipelas vaccine antigen in $\mathrm{r} E$ coli fed-batch cultures. Springerplus $2: 1-12$. https://doi.org/10.1186/2193-1801-2-322

da Silva AJ, de Cunha J, S, Hreha T, Micocci KC, Selistre-de-Araujo HS, Barquera B, Koffas MAG, (2021) Metabolic engineering of E coli for pyocyanin production. Metab Eng 64:15-25. https://doi. org/10.1016/j.ymben.2021.01.002
Danquah MK, Forde GM (2007) Growth medium selection and its economic impact on plasmid DNA production. J Biosci Bioeng 104:490-497. https://doi.org/10.1263/jbb.104.490

Donovan RS, Robinson CW, Glick BR (1996) Review: optimizing inducer and culture conditions for expression of foreign proteins under the control of the lac promoter. J Ind Microbiol 16:145-154. https://doi.org/10.1007/bf01569997

Einsfeldt K, Baptista J, Júnior S, Paula A, Argondizzo C, Alberto M, Lívio T, Alves M, Volcan R, Leites A (2011) Cloning and expression of protease ClpP from Streptococcus pneumoniae in Escherichia coli study of the influence of kanamycin and IPTG concentration on cell growth, recombinant protein production and plasmid stability. Vaccine 29:7136-7143. https://doi.org/10. 1016/j.vaccine.2011.05.073

Ferreira G, Azzoni AR, Freitas S (2018) Biotechnology for biofuels techno-economic analysis of the industrial production of a low-cost enzyme using E. coli: the case of recombinant $\beta$-glucosidase. Biotechnol Biofuels 11:1-13. https://doi.org/10. 1186/s13068-018-1077-0

Figueiredo DB, Carvalho E, Santos MP, Kraschowetz S, Zanardo RT, Campani G, Silva GG, Sargo CR, Horta ACL, de Giordano RC, Miyaji EN, Zangirolami TC, Cabrera-Crespo J, Gonçalves VM (2017) Production and purification of an untagged recombinant pneumococcal surface protein A (PspA4Pro) with high-purity and low endotoxin content. Appl Microbiol Biotechnol 101:23052317. https://doi.org/10.1007/s00253-016-7983-9

Fong BA, Wood DW (2010) Expression and purification of ELPintein-tagged target proteins in high cell density E. coli fermentation. Microb Cell Fact 77:1-12. https://doi.org/10.1186/ 1475-2859-9-77

Garcia-Ochoa F, Gomez E (2009) Bioreactor scale-up and oxygen transfer rate in microbial processes: an overview. Biotechnol Adv 27:153-176. https://doi.org/10.1016/j.biotechadv.2008.10.006

Gnopo YMD, Misra A, Hsu HL, DeLisa MP, Daniel S, Putnam D (2020) Induced fusion and aggregation of bacterial outer membrane vesicles: experimental and theoretical analysis. J Colloid Interface Sci 578:522-532. https://doi.org/10.1016/j.jcis.2020. 04.068

Goldrick S, Sandner V, Cheeks M, Turner R, Farid SS, McCreath G, Glassey J (2020) Multivariate data analysis methodology to solve data challenges related to scale-up model validation and missing data on a micro-dioreactor system. Biotechnol J 15:1-12. https:// doi.org/10.1002/biot.201800684

González-Miro M, Rodríguez-Noda L, Fariñas-Medina M, GarcíaRivera D, Vérez-Bencomo V, Rehm BHA (2017) Self-assembled particulate PsaA as vaccine against Streptococcus pneumoniae infection. Heliyon 3:e00291. https://doi.org/10.1016/j.heliyon. 2017.e00291

Grossman TH, Kawasaki ES, Punreddy SR, Osburne MS (1998) Spontaneous cAMP-dependent derepression of gene expression in stationary phase plays a role in recombinant expression instability. 209:95-103. doi: https://doi.org/10.1016/s0378

Haughney SL, Petersen LK, Schoofs AD, Ramer-Tait AE, King JD, Briles DE, Wannemuehler MJ, Narasimhan B (2013) Retention of structure, antigenicity, and biological function of pneumococcal surface protein A (PspA) released from polyanhydride nanoparticles. Acta Biomater 9:8262-8271. https://doi.org/10.1016/j. actbio.2013.06.006

Hayashi K, Itoh S, Morikawa A, Onozaki K, Taki S, Tsuji T, Hida S (2019) Staphylococcal $\alpha$-hemolysin does not induce cell damage in murine mast cells but it augments the degranulation induced by FceRI cross-linking and ionomycin. Biochem Biophys Res Commun 508:263-269. https://doi.org/10.1016/j.bbrc.2018.11.113

Horta ACL, Sargo CRS, da Silva AJS, de Gonzaga MC, dos Santos MPS, Gonçalves VMG, Zangirolami TC, de Giordano RC (2012) Intensification of high cell-density cultivations of $\mathrm{r}$ E. coli for 
production of S. pneumoniae antigenic surface protein, PspA3, using model-based adaptive control. Bioprocess Biosyst Eng 35:1269-1280. https://doi.org/10.1007/s00449-012-0714-4

Horta ACL, Silva AJ, Sargo CR, Velez AM, Gonzaga MC, Giordano RC, Zangirolami TC (2014) A supervision and control tool based on artificial intelligence for high cell density cultivations. Brazilian J Chem Eng 31:457-468. https://doi.org/10.1590/0104-6632. 20140312s00002304

Hsu SH, Chang MY, Lin SM, Ko YC, Chou LF, Tian YC, Hung CC, Yang CW (2021) Peptidoglycan mediates Leptospira outer membrane protein Loa22 to toll-like receptor 2 for inflammatory interaction: a novel innate immune recognition. Sci Rep 11:1-16. https://doi.org/10.1038/s41598-020-79662-8

Hunt JP, Zhao EL, Soltani M, Frei M, Nelson JAD, Bundy BC (2019) Streamlining the preparation of "endotoxin-free" ClearColi cell extract with autoinduction media for cell-free protein synthesis of the therapeutic protein crisantaspase. Synth Syst Biotechnol 4:220-224. https://doi.org/10.1016/j.synbio.2019.11.003

Jedrzejas MJ, Hollingshead SK, Lebowitz J, Chantalat L, Briles DE, Lamani E (2000) Production and characterization of the functional fragment of pneumococcal surface protein A. Arch Biochem Biophys 373:116-125. https://doi.org/10.1006/abbi.1999.1544

Jedrzejas MJ, Lamani E, Becker RS (2001) Characterization of selected strains of pneumococcal surface protein A. J Biol Chem 276:33121-33128. https://doi.org/10.1074/jbc.M103304200

Jobin PG, Solis N, Machado Y, Bell PA, Kwon NH, Kim S, Overall CM, Butler GS (2019) Matrix metalloproteinases inactivate the proinflammatory functions of secreted moonlighting tryptophanyl-tRNA synthetase. J Biol Chem 294:12866-12879. https://doi. org/10.1074/jbc.RA119.009584

Kaur J, Kumar A, Kaur J (2018) Strategies for optimization of heterologous protein expression in E. coli: roadblocks and reinforcements. Int J Biol Macromol 106:803-822. https://doi.org/10.1016/j.ijbio mac.2017.08.080

Kim J, Kim KH (2017) Effects of minimal media vs. complex media on the metabolite profiles of Escherichia coli and Saccharomyces cerevisiae. Process Biochem 57:64-71. https://doi.org/10.1016/j. procbio.2017.04.003

Kobayashi M, Kitano T, Nishiyama S, Sanjo H, Onozaki K, Taki S, Itoh S, Hida S (2019) Staphylococcal superantigen-like 12 activates murine bone marrow derived mast cells. Biochem Biophys Res Commun 511:350-355. https://doi.org/10.1016/j.bbrc.2019. 02.052

Laemmli UK (1970) Cleavage of structural proteins during the assembly of the bacteriophage T4. Nature 227:680-685. https://doi.org/ $10.1038 / 227680 \mathrm{a0}$

Lagousi T, Basdeki P, Routsias J, Spoulou V (2019) Novel proteinbased pneumococcal vaccines: assessing the use of distinct protein fragments instead of full-length proteins as vaccine antigens. Vaccines 7. doi: https://doi.org/10.3390/vaccines7010009

Lamani E, McPherson DT, Hollingshead SK, Jedrzejas MJ (2000) Production, characterization, and crystallization of truncated forms of pneumococcal surface protein A from Escherichia coli. Protein Expr Purif 20:379-388. https://doi.org/10.1006/prep.2000.1320

Lecina M, Sarró E, Casablancas A, Gòdia F, Cairó JJ (2013) Regular article IPTG limitation avoids metabolic burden and acetic acid accumulation in induced fed-batch cultures of Escherichia coli M15 under glucose limiting conditions. Biochem Eng J 70:78-83. https://doi.org/10.1016/j.bej.2012.10.006

Lee SY (1996) High cell-density culture of Escherichia coli. Trends Biotechnol 14:98-105. https://doi.org/10.1016/0167-7799(96) 80930-9

Li Z, Zhang X, Tan T (2006) Lactose-induced production of human soluble B lymphocyte stimulator ( hsBLyS ) in E. coli with different culture strategies. Biotechnol Lett 28:477-483. https://doi. org/10.1007/s10529-006-0002-y
Liang WS, Fang TY, Lin HT, Liu TC, Lu WJ, Tzou WS, Tang SJ, Lin FP, Liu SM, Pan CL (2015) Cloning, expression, and characterization of Pseudomonas vesicularis MA103 $\beta$-1,3-xylanase in Escherichia coli ClearColi BL21(DE3). Fish Sci 81:1135-1143. https://doi.org/10.1007/s12562-015-0933-0

López L, Chiribao ML, Girard MC, Gómez KA, Carasi P, Fernandez M, Hernandez Y, Robello C, Freire T, Piñeyro MD (2021) The cytosolic tryparedoxin peroxidase from Trypanosoma cruzi induces a pro-inflammatory Th1 immune response in a peroxidatic cysteine-dependent manner. Immunology 163:46-59. https://doi.org/10.1111/imm.13302

Lucigen (2016) MA145 ClearColi ${ }^{\circledR}$ BL21(DE3) electrocompetent cells. Tucson, Arizona

Mamat U, Wilke K, Bramhill D, Schromm AB, Lindner B, Kohl TA, Corchero JL, Villaverde A, Schaffer L, Head SR, Souvignier C, Meredith TC, Woodard RW (2015) Detoxifying Escherichia coli for endotoxin-free production of recombinant proteins. Microb Cell Fact 14:1-15. https://doi.org/10.1186/s12934-015-0241-5

Martínez-Donato G, Piniella B, Aguilar D, Olivera S, Pérez A, Castañedo Y, Alvarez-Lajonchere L, Dueñas-Carrera S, Lee JW, Burr N, Gonzalez-Miro M, Rehm BHA (2016) Protective $\mathrm{T}$ cell and antibody immune responses against Hepatitis $\mathrm{C}$ virus achieved using a biopolyester-bead-based vaccine delivery system. Clin Vaccine Immunol 23:370-378. https://doi.org/10. 1128/cvi.00687-15

Masarapu H, Patel BK, Chariou PL, Hu H, Gulati NM, Carpenter BL, Ghiladi RA, Shukla S, Steinmetz NF (2017) Physalis mottle virus-like particles as nanocarriers for imaging reagents and drugs. Biomacromol 18:4141-4153. https://doi.org/10.1021/acs. biomac.7b01196

Michiels JF, Barbau J, De Boel S, Dessy S, Agathos SN, Schneider YJ (2011) Characterisation of beneficial and detrimental effects of a soy peptone, as an additive for $\mathrm{CHO}$ cell cultivation. Process Biochem 46:671-681. https://doi.org/10.1016/j.procbio. 2010.11 .012

Miyaji EN, Oliveira MLS, Carvalho E, Ho PL (2013) Serotype-independent pneumococcal vaccines. Cell Mol Life Sci 70:3303-3326. https://doi.org/10.1007/s00018-012-1234-8

Montgomery DC (2013) Design and analysis of experiments, 8th edn. John Wiley \& Sons Inc, Hoboken

Moon S, Kong B, Jung YH, Kim Y, Yu S, Park J, bum, Shin J, Kweon DH, (2018) Endotoxin-free purification of recombinant membrane scaffold protein expressed in Escherichia coli. Process Biochem 66:230-236. https://doi.org/10.1016/j.procbio.2017.12.005

Moreno AT, Oliveira MLS, Ferreira DM, Ho PL, Darrieux M, Leite LCC, Ferreira JMC, Pimenta FC, Andrade ALSS, Miyaji EN (2010) Immunization of mice with single PspA fragments induces antibodies capable of mediating complement deposition on different pneumococcal strains and cross-protection. Clin Vaccine Immunol 17:439-446. https://doi.org/10.1128/CVI.00430-09

Nguyen TKO, Vu TL, Nguyen MQ, Ta HKK, Park KS, Kim SH, Kim CJ, Jang YJ, Choe H (2021) Soluble prokaryotic overexpression and purification of human gm-csf using the protein disulfide isomerase b' a' domain. Int J Mol Sci 22:5267. https://doi.org/10. 3390/ijms22105267

Olsson L, Nielsen J (1997) On-line and in situ monitoring of biomass in submerged cultivations. Trends Biotechnol 15:517-522. https:// doi.org/10.1016/s0167-7799(97)01136-0

Park JH, Bong JH, Jung J, Sung JS, Lee GY, Kang MJ, Pyun JC (2021) Microbial biosensor for Salmonella using anti-bacterial antibodies isolated from human serum. Enzyme Microb Technol 144:109721. https://doi.org/10.1016/j.enzmictec.2020.109721

Perciani CT, Barazzone GC, Goulart C, Carvalho E, Cabrera-Crespo J, Gonçalves VM, Leite LCC, Tanizaki MM (2013) Conjugation of polysaccharide 6B from Streptococcus pneumoniae with pneumococcal surface protein A: PspA conformation and its effect on the 
immune response. Clin Vaccine Immunol 20:858-866. https://doi. org/10.1128/CVI.00754-12

Piao Z, Akeda Y, Takeuchi D, Ishii KJ, Ubukata K, Briles DE, Tomono K, Oishi K (2014) Protective properties of a fusion pneumococcal surface protein A (PspA) vaccine against pneumococcal challenge by five different PspA clades in mice. Vaccine 32:5607-5613. https://doi.org/10.1016/j.vaccine.2014.07.108

Planesse C, Nativel B, Iwema T, Gasque P, Robert-Da Silva C, Viranaïcken W (2015) Recombinant human HSP60 produced in ClearColi ${ }^{\mathrm{TM}}$ BL21(DE3) does not activate the NFKB pathway. Cytokine 73:190-195. https://doi.org/10.1016/j.cyto.2015.01.028

Pooe OJ, Köllisch G, Heine H, Shonhai A (2017) Plasmodium falciparum heat shock protein 70 lacks immune modulatory activity. Protein Pept Lett 24:503-510. https://doi.org/10.2174/092986652466617 0214141909

Qiao J, Dong C, Wang X, Liu Y, Ma L (2019) One-step production of bioactive human lipopolysaccharide binding protein from LPSeliminated E. coli. Protein Expr Purif 157:17-20. https://doi.org/ 10.1016/j.pep.2019.01.008

Ramachandran G (2014) Gram-positive and gram-negative bacterial toxins in sepsis: a brief review. Virulence 5:213-218. https://doi.org/ 10.4161/viru.27024

Ran G, Tan D, Zhao J, Fan F, Zhang Q, Wu X, Fan P, Fang X, Lu X (2019) Functionalized polyhydroxyalkanoate nano-beads as a stable biocatalyst for cost-effective production of the rare sugar D-allulose. Bioresour Technol 289:121673. https://doi.org/10.1016/j.biortech. 2019.121673

Rao C V, Koirala S (2014) Micro commentary black and white with some shades of grey: the diverse responses of inducible metabolic pathways in Escherichia coli. 93:1079-1083. doi: https://doi.org/ 10.1111/mmi.12734

Rodrigues MI, Iemma AF (2014) Experimental design and process optimization, 1. Ed. CRC Press, Boca Raton.

Rosano GL, Ceccarelli EA (2014) Recombinant protein expression in Escherichia coli: advances and challenges. Front Microbiol 5:1-17. https://doi.org/10.3389/fmicb.2014.00172

Sankaran S, del Campo A (2019) Optoregulated protein release from an engineered living material. Adv Biosyst 3:3-9. https://doi.org/10. 1002/adbi.201800312

Sankaran S, Becker J, Wittmann C, del Campo A (2019) Optoregulated drug release from an engineered living material: self-replenishing drug depots for long-term, light-regulated delivery. Small 15:1-6. https://doi.org/10.1002/smll.201804717

Schneier M, Razdan S, Miller AM, Briceno ME, Barua S (2020) Current technologies to endotoxin detection and removal for biopharmaceutical purification. Biotechnol Bioeng 117:2588-2609. https://doi. org/10.1002/bit.27362

Segovia-Trinidad CL, Quaas B, Li Z, Lavrentieva A, Roger Y, Scheper T, Hoffmann A, Rinas U (2021) Refolding, purification, and characterization of constitutive-active human-Smad8 produced as inclusion bodies in ClearColi® BL21 (DE3). Protein Expr Purif 184:105878. https://doi.org/10.1016/j.pep.2021.105878

Shiloach J, Fass R (2005) Growing E. coli to high cell density a historical perspective on method development. Biotechnol Adv 23:345-357. https://doi.org/10.1016/j.biotechadv.2005.04.004

Shuler ML, Kargi F (2002) Bioprocess bioengineering: basic concepts, 2nd edn. Prentice Hall, Englewood Cliffs

Song HW, Yoo G, Bong JH, Kang MJ, Lee SS, Pyun JC (2019) Surface display of sialyltransferase on the outer membrane of Escherichia coli and ClearColi. Enzyme Microb Technol 128:1-8. https://doi. org/10.1016/j.enzmictec.2019.04.017

Studier FW (2005) Protein production by auto-induction in high-density shaking cultures. Protein Expr Purif 41:207-234. https://doi.org/10. 1016/j.pep.2005.01.016
Taguchi S, Ooi T, Mizuno K, Matsusaki H (2015) Advances and needs for endotoxin-free production strains. Appl Microbiol Biotechnol 99:9349-9360. https://doi.org/10.1007/s00253-015-6947-9

Tomczak A, Singh K, Gittis AG, Lee J, Garboczi DN, Murphy PM (2017) Biochemical and biophysical characterization of cytokine-like protein 1 (CYTL1). Cytokine 96:238-246. https://doi.org/10.1016/j. cyto.2017.04.023

Ueda T, Akuta T, Kikuchi-Ueda T, Imaizumi K, Ono Y (2016) Improving the soluble expression and purification of recombinant human stem cell factor (SCF) in endotoxin-free Escherichia coli by disulfide shuffling with persulfide. Protein Expr Purif 120:99-105. https://doi. org/10.1016/j.pep.2015.12.015

Viranaicken W, Nativel B, Krejbich-Trotot P, Harrabi W, Bos S, El Kalamouni C, Roche M, Gadea G, Desprès P (2017) ClearColi BL21(DE3)-based expression of Zika virus antigens illustrates a rapid method of antibody production against emerging pathogens. Biochimie 142:179-182. https:// doi.org/10.1016/j.biochi.2017.09.011

Von den Eichen N, Bromig L, Sidarava V, Marienberg H, Weuster-Botz D (2021) Automated multi-scale cascade of parallel stirred-tank bioreactors for fast protein expression studies. J Biotechnol 332:103-113. https://doi.org/10.1016/j.jbiotec.2021.03.021

Wang G, Geisbrecht B, Rueter C, Hardwidge P (2017) Enterotoxigenic Escherichia coli flagellin inhibits TNF-induced NF- $\mathrm{KB}$ activation in intestinal epithelial cells. Pathogens 6:18. https://doi.org/10.3390/ pathogens6020018

Watkins HC, Pagan CL, Childs HR, Posada S, Chau A, Rios J, Guarino C, DeLisa MP, Whittaker GR, Putnam D (2017a) A single dose and long lasting vaccine against pandemic influenza through the controlled release of a heterospecies tandem M2 sequence embedded within detoxified bacterial outer membrane vesicles. Vaccine 35:5373-5380. https://doi.org/10.1016/j.vaccine.2017.08.013

Watkins HC, Rappazzo CG, Higgins JS, Sun X, Brock N, Chau A, Misra A, Cannizzo JPB, King MR, Maines TR, Leifer CA, Whittaker GR, DeLisa MP, Putnam D (2017b) Safe recombinant outer membrane vesicles that display M2e elicit heterologous influenza protection. Mol Ther 25:989-1002. https://doi.org/10.1016/j.ymthe.2017.01.010

Wilding KM, Hunt JP, Wilkerson JW, Funk PJ, Swensen RL, Carver WC, Christian ML, Bundy BC (2019a) Endotoxin-free E. coli-based cellfree protein synthesis: pre-expression endotoxin removal approaches for on-demand cancer therapeutic production. Biotechnol J 14:1-6. https://doi.org/10.1002/biot.201800271

Wilding KM, Zhao EL, Earl CC, Bundy BC (2019b) Thermostable lyoprotectant-enhanced cell-free protein synthesis for on-demand endotoxin-free therapeutic production. N Biotechnol 53:73-80. https://doi.org/10.1016/j.nbt.2019.07.004

Xu J, Banerjee A, Pan S, Jian Z (2012) Galactose can be an inducer for production of therapeutic proteins by auto-induction using E. coli BL21 strains. Protein Expr Purif 83:30-36. https://doi.org/10.1016/j. pep.2012.02.014

Yang JD, Lu C, Stasny B, Henley J, Guinto W, Gonzalez C, Gleason J, Fung M, Collopy B, Benjamino M, Gangi J, Hanson M, Ille E (2007) Fed-batch bioreactor process scale-up from 3-L to 2,500-L scale for monoclonal antibody production from cell culture. Biotechnol Bioeng 98:141-154. https://doi.org/10.1002/bit.21413

Yoo G, Dilkaute C, Bong JH, Song HW, Lee M, Kang MJ, Jose J, Pyun JC (2017) Autodisplay of the La/SSB protein on LPS-free E. coli for the diagnosis of Sjögren's syndrome. Enzyme Microb Technol 100:1-10. https://doi.org/10.1016/j.enzmictec.2017.01.007

Zhang J, Greasham R (1999) Chemically defined media for commercial fermentations. Appl Microbiol Biotechnol 51:407-421. https://doi. org/10.1007/s002530051411

Publisher's note Springer Nature remains neutral with regard to jurisdictional claims in published maps and institutional affiliations. 